\title{
Multiple Distinct Signal Pathways, Including an Autocrine Neurotrophic Mechanism, Contribute to the Survival-Promoting Effect of Depolarization on Spiral Ganglion Neurons In Vitro
}

\author{
Marlan R. Hansen, Xiang-Ming Zha, Jinwoong Bok, and Steven H. Green \\ Departments of Biological Sciences and Otolaryngology, University of lowa, lowa City, lowa 52242
}

We have shown previously that BDNF, neurotrophin-3 (NT-3), chlorphenylthio-cAMP (cpt-cAMP) (a permeant cAMP analog), and membrane depolarization promote spiral ganglion neuron (SGN) survival in vitro in an additive manner, depolarization having the greatest efficacy. Expression of both BDNF and of NT-3 is detectable in cultured SGNs after plating in either depolarizing or nondepolarizing medium. These neurotrophins promote survival by an autocrine mechanism; TrkB-lgG or TrkC-IgG, which block neurotrophin binding to, respectively, TrkB and TrkC, partially inhibit the trophic effect of depolarization. The mitogen-activated protein kinase kinase inhibitor PD98059 and the phosphatidylinositol-3-OH kinase inhibitor LY294002 both abolish trophic support by neurotrophins but only partially inhibit support by depolarization. Inhibition by these compounds is not additive with inhibition by Trk-lgGs. The cAMP antagonist Rp-adenosine-3',5'-cyclic-phosphorothioate (Rp-cAMPS) abolishes survival attributable to cptcAMP but has no effect on that attributable to neurotrophins, nor do inhibitors of neurotrophin-dependent survival affect survival attributable to cpt-cAMP. However, Rp-cAMPS does partially inhibit depolarization-dependent survival, an inhibition that is additive with that by Trk-lgGs, PD98059, or LY294002. Moreover, Rp-cAMPS prevents depolarization-dependent survival of PC12 cells maintained in subthreshold levels of NGF. Inhibition of $\mathrm{Ca}^{2+} /$ calmodulin-dependent protein kinases (CaMKs) with KN-62 reduces SGN survival independently of Rp-cAMPS, Trk-lgGs, and LY294002 and additively with them. Combined inhibition of Trk, CAMP, and CaMK signaling prevents depolarization-dependent survival. Thus, survival of SGNs under depolarizing conditions involves additivity among a depolarization-independent autocrine pathway, a cAMPdependent pathway, and a CaMK-dependent pathway.

Key words: membrane depolarization; spiral ganglion neuron; cell survival; neurotrophic factor; BDNF; NT-3; CAMP; MAP kinase; ERK; phosphatidylinositol-3-OH kinase; signal transduction; autocrine mechanism
Neuronal survival is supported by neurotrophic factors, such as the neurotrophins, and by membrane depolarization. Substantial progress has been made recently in understanding the intracellular signals recruited by neurotrophic factors to prevent cell death (Segal and Greenberg, 1996). Neurotrophins signal through the Trk family of receptor protein-tyrosine kinases to activate at least two intracellular signal pathways implicated in promotion of neuronal survival: the Ras-MAP kinase (ERK) pathway (Xia et al., 1995; Yan and Greene, 1998; Bonni et al., 1999) and the phosphatidylinositol-3-OH kinase (PI3K)-protein kinase B (PKB, Akt) pathway (Yao and Cooper, 1995; D’Mello et al., 1997; Dudek et al., 1997; Miller et al., 1997).

Depolarization is an important trophic stimulus accounting, at least in part, for neurotrophic support by presynaptic cells; block-

Received Aug. 30, 1999; revised Nov. 28, 2000; accepted Dec. 7, 2000.

This work was supported by National Institutes of Health Grant DC02961 (S.H.G.), an American Otological Society Research grant (S.H.G.), a grant from the Deafness Research Foundation (S.H.G.), and a grant from the Academy of Otolaryngology (M.R.H.). M.R.H. was supported by National Institutes of Health Training Grant DC00040. These studies made use of facilities and services provided by the University of Iowa Diabetes and Endocrinology Research Core, funded by National Institutes of Health Grant DK25295. We thank Becky Kueter for technical assistance, Dr. Stephen Heard for assistance with statistics, and members of the Green laboratory for comments on this manuscript. We also thank Dr. Alan Saltiel (Parke-Davis, Ann Arbor, MI) for providing PD98059 and Genentech for providing the neurotrophins, antibodies to neurotrophins, and Trk-IgG immunoadhesins used in these studies.

Correspondence should be addressed to Steven H. Green, Department of Biological Sciences, University of Iowa, 138 Biology Building, Iowa City, IA 522421324. E-mail: steven-green@uiowa.edu.

Copyright (C) 2001 Society for Neuroscience $0270-6474 / 01 / 212256-12 \$ 15.00 / 0$ ade of membrane electrical activity in vivo (Wright, 1981; Furber et al., 1987; Meriney et al., 1987; Maderdrut et al., 1988; Rubel et al., 1990; Catsicas et al., 1992; Galli-Resta et al., 1993) and in vitro (Lipton, 1986; Ruitjer et al., 1991) reduces neuronal survival. Depolarization permits neuronal survival in vitro in the absence of added neurotrophic factors (Scott and Fisher, 1970; Bennett and White, 1979; Chalazonitis and Fischbach, 1980; Wakade et al., 1983; Gallo et al., 1987).

$\mathrm{Ca}^{2+}$ influx through L-type $\mathrm{Ca}^{2+}$ channels appears to be a necessary first step (Gallo et al., 1987; Collins and Lile, 1989; Koike et al., 1989; Franklin et al., 1995; Hegarty et al., 1997) for promotion of survival by depolarization, implicating $\mathrm{Ca}^{2+}$ as a second messenger for survival signaling. $\mathrm{Ca}^{2+} /$ calmodulindependent protein kinases (CaMKs) are activated by $\mathrm{Ca}^{2+}$ (Hanson and Schulman, 1992) and thus could mediate depolarization-dependent survival, as shown by Hack et al. (1993). Also, cAMP is a survival signal for neurons (Rydel and Greene, 1988; Kaiser and Lipton, 1990; D’Mello et al., 1993; Galli et al., 1995; Meyer-Franke et al., 1995; Hegarty et al., 1997; Hanson et al., 1998), and $\mathrm{Ca}^{2+}$ elevates intracellular cAMP levels via $\mathrm{Ca}^{2+}$ /calmodulin-dependent adenylyl cyclase (Cooper et al., 1995). Thus, a cAMP-dependent pathway might also mediate survival-promoting effects of depolarization, as seems to be the case in retinal ganglion cells (Meyer-Franke et al., 1995). Depolarization may promote survival by stimulating an autocrine neurotrophic mechanism: synthesis and release of neurotrophic factors by the neurons themselves (Ghosh et al., 1994). Neurotrophins promote survival via PI3K or ERK pathways (Xia et al., 
1995; Yao and Cooper, 1995; D’Mello et al., 1997; Dudek et al., 1997; Miller et al., 1997; Bonni et al., 1999; Mazzoni et al., 1999), and depolarization can also activate these pathways (Rosen et al., 1994; Lev et al., 1995; Miller et al., 1997; Vaillant et al., 1999), raising the possibility that one or both directly mediate promotion of survival by depolarization. Such a role for PI3K-PKB is supported by some (Miller et al., 1997; Vaillant et al., 1999) but not all (D'Mello et al., 1997) studies.

Studies of the auditory system highlight the significance of afferent input in trophic support of neurons and the important role of electrical activity therein. Spiral ganglion neurons (SGNs) die after deafferentation because of loss of hair cells (Spoendlin, 1975; Webster and Webster, 1981; Koitchev et al., 1982; Bichler et al., 1983). Electrical stimulation via an electrode implanted in the cochlea promotes survival of deafferented SGNs (Wong-Riley et al., 1981; Lousteau, 1987; Hartshorn et al., 1991; Leake et al., 1991, 1992; Lustig et al., 1994), supporting a role for membrane electrical activity in SGN survival.

SGNs express TrkB and TrkC (Mou et al., 1997) and are supported in vitro by BDNF and by neurotrophin-3 (NT-3) (Avila et al., 1993; Pirvola et al., 1994; Vazquez et al., 1994; Zheng et al., 1995; Hegarty et al., 1997), as well as by a permeant cAMP analog (Hegarty et al., 1997), indicating that neurotrophin- and cAMPdependent intracellular signal pathways promote survival of SGNs. Depolarization, accomplished by raising extracellular $\left[\mathrm{K}^{+}\right]$to $30 \mathrm{~mm}$ or by adding veratridine, is an even more effective survival-promoting stimulus for cultured SGNs than are neurotrophins or chlorphenylthio-cAMP (cpt-cAMP) (Hegarty et al., 1997).

Using cultured SGNs, which have a robust trophic response to depolarization, we show that the response is complex and involves multiple intracellular signal pathways. At least three distinct pathways independently contribute to the total survivalpromoting effect of depolarization. An autocrine neurotrophic pathway, which exists in SGNs independently of depolarization, is necessary for part of the survival-promoting effect of depolarization. A second pathway involves a cAMP-dependent mechanism and accounts for an additional part of the survivalpromoting effect of depolarization. Finally, we show that the autocrine mechanism and cAMP pathways together do not account for the entire trophic effect of depolarization, implying the existence of at least one additional pathway. ERKs and PI3K participate in promotion of survival by depolarization to the extent that they are required for neurotrophin function but are not required for other intracellular signaling attributable to depolarization.

\section{MATERIALS AND METHODS}

Cell culture and quantification of cell survival. Dissociated neonatal rat spiral ganglion cell cultures containing spiral ganglion neurons and non-neuronal cells were prepared by a modification of the method of Lefebvre et al. (1991) and maintained in N2-supplemented serum-free, high-glucose DMEM supplemented as described previously (N2 media) (Hegarty et al., 1997). The protocol was approved by the University of Iowa Animal Care and Use Committee.

Briefly, 5-d-old rat pups were killed by decapitation, and cochleae were aseptically removed from the temporal bone and placed in ice-cold PBS. The bony cochlear capsule was removed, followed by the spiral ligament. The organ of Corti was then removed, transecting the outer radial fibers, leaving the spiral ganglion neurons within the modiolus. Modiolar bone was removed, and surrounding connective tissue was incompletely removed. Ganglia were collected in ice-cold HBSS. Enzymatic dissociation was then performed in $\mathrm{Ca}^{2+} / \mathrm{Mg}^{2+}$-free HBSS with $0.1 \%$ collagenase, $0.1 \%$ trypsin, and $0.01 \%$ DNase I (Boehringer Mannheim, Indianapolis, IN) in a gently shaking $37^{\circ} \mathrm{C}$ water bath for $25 \mathrm{~min}$. Fetal calf serum (Life
Technologies, Gaithersburg, MD) was added to $10 \%$ to inhibit enzymatic activity, followed by three washes in serum-free DMEM and one wash in culture medium (see below). The ganglia were mechanically dissociated using two fire-polished reduced-orifice glass Pasteur pipettes, the second considerably more narrow than the first. The ganglia were gently triturated $\sim 15$ times with each pipette and diluted with culture medium $(8-10$ ganglia/2 $\mathrm{ml}$ ).

Equal volumes of dissociated spiral ganglion cell suspension were plated in 96 well tissue culture plates (Corning, Corning, NY) that had been treated with polyornithine $(0.1 \mathrm{mg} / \mathrm{ml}$ in $10 \mathrm{~mm}$ Na borate buffer $)$ for $1 \mathrm{hr}$ at room temperature, followed by laminin $(20 \mu \mathrm{g} / \mathrm{ml}$; Life Technologies) overnight at $4^{\circ} \mathrm{C}$. Cells were grown in $100 \mu \mathrm{l}$ of culture media at $37^{\circ} \mathrm{C}$ in a $6.5 \% \mathrm{CO}_{2}$ incubator. Trophic agents and inhibitors were added $2-3 \mathrm{hr}$ after plating. In all chronic elevated $\left[\mathrm{K}^{+}\right]_{\mathrm{o}}$ depolarization experiments, $\mathrm{Na}^{+}$was replaced by equimolar $\mathrm{K}^{+}$to maintain osmolarity.

Neuronal counts were performed after $48 \mathrm{hr}$ in culture as described previously (Hegarty et al., 1997). Briefly, the cells were fixed with fresh $4 \%$ paraformaldehyde for $20 \mathrm{~min}$ at room temperature. The neurons were identified by immunocytochemistry: labeling with anti-neuronspecific enolase (NSE) antibody (Zymed, South San Francisco, CA), followed sequentially by a horse-radish peroxidase (HRP)-conjugated goat anti-rabbit secondary antibody and visualization with 3-amino-9ethylcarbazole. All neurons in each well were counted. Criteria for neuronal viability were NSE immunoreactivity and a nucleus that was visible and not pyknotic. Each condition was done in triplicate and repeated on at least three different occasions.

As noted previously (Hegarty et al., 1997), plating efficiency and initial survival of spiral ganglion neurons is relatively low, presumably because of the trauma of the preparation. The plating efficiency is typically $60-70 \%$. However, of these plated neurons, only a fraction survive in long-term culture, regardless of the culture conditions. Thus, in $30 \mathrm{~mm}$ $\left[\mathrm{K}^{+}\right]_{\mathrm{o}}(30 \mathrm{~K})$, the typical control condition used in this study, $\sim 25 \%$ of the plated spiral ganglion neurons survive to $48 \mathrm{hr}$. Survival is improved to $50-60 \%$ of the plated spiral ganglion neurons if other neurotrophic stimuli are present in addition to $30 \mathrm{~K}$, as described previously (Hegarty et al., 1997). When maintained with survival-promoting stimuli, nearly all of the spiral ganglion neurons that die after plating do so within the first 12-24 hr. The number of surviving spiral ganglion neurons in $30 \mathrm{~K}$ or other survival-promoting conditions remains fairly constant after 24-48 $\mathrm{hr}$ in culture but continues to decline if plated without such survivalpromoting stimuli. Thus, we assessed neuronal survival $48 \mathrm{hr}$ after plating.

PC12 cells were maintained as described previously (Green, 1995) in RPMI with $10 \%$ donor horse serum and $5 \%$ fetal calf serum on collagenized tissue culture plates. PC12 cell survival was assessed as by Mesner et al. (1995) by staining with trypan blue and counting dye-excluding cells with a hemacytometer.

Immunocytochemical detection of neurotrophins. Dissociated spiral ganglion cell cultures were plated on microwell glass slides (Electron Microscopy Sciences, Fort Washington, PA) treated with polyornithine and laminin as above. The cells were fixed after $24-48 \mathrm{hr}$ with freshly prepared $4 \%$ paraformaldehyde in PBS for $20 \mathrm{~min}$ at room temperature, washed three times with PBS, and permeabilized with $0.2 \%$ Triton X-100 in PBS for $20 \mathrm{~min}$. The cells were then incubated in blocking buffer $(10 \%$ normal goat serum plus $2 \%$ bovine serum albumin plus $0.2 \%$ Triton $\mathrm{X}-100$ in PBS) for $1 \mathrm{hr}$ at room temperature, followed by an overnight incubation at $4^{\circ} \mathrm{C}$ with primary antibodies diluted in blocking buffer. Rabbit anti-BDNF or anti-NT-3 antiserum (Genentech, San Francisco, CA or Santa Cruz Biotechnology, Santa Cruz, CA), diluted 1:200, was combined with mouse anti-NF-200 monoclonal antibody (Sigma, St. Louis, MO), diluted 1:500. After three washes with $0.2 \%$ Triton X-100 in PBS, the cells were incubated with the secondary antibodies in blocking buffer for $1 \mathrm{hr}$ at room temperature. Rhodamine-conjugated goat antirabbit antibody (Sigma), diluted 1:300, to detect NT-3 or BDNF staining, was combined with FITC-conjugated goat anti-mouse antibody (Sigma), diluted 1:500, to detect NF-200 staining. The slides were again washed three times with $0.2 \%$ Triton X-100 in PBS and coverslipped using $90 \%$ glycerol plus $10 \%$ PBS plus $1 \mathrm{mg} / \mathrm{ml} p$-phenylenediamine. For detection of Trk, chicken anti-panTrk-IgY (Promega, Madison, WI) was used at a dilution of 1:250 and visualized with FITC-conjugated goat anti-IgY (Aves Labs Inc., Tigard, OR) at a dilution of 1:400.

The cells were viewed with a Leica (Nussloch, Germany) Leitz DMR microscope equipped with fluorescence filters with a maximum excitation of $535 \mathrm{~nm}$ and maximum emission of $610 \mathrm{~nm}$ for detection of rhodamine 
and a maximum excitation of $480 \mathrm{~nm}$ and maximum emission of $535 \mathrm{~nm}$ for detection of FITC. Digital images were captured using a Color Coolview CCD camera (Photonic Science, East Sussex, UK) and IPLab Spectrum software (Signal Analytics Corp., Vienna, VA) and prepared for publication using Adobe Photoshop and Illustrator (Adobe Systems, San Jose, CA). Immunofluorescence was quantified in digitized images using NIH Image software, which, with the documentation, was obtained from the National Institutes of Health web site (http://rsb.info.nih.gov/ nih-image/). Images used were captured using identical settings for light and camera to minimize contrast and brightness differences and were then normalized by equalizing background cell fluorescence in all images. Oval or circular selection outlines were drawn around the regions of the neuronal cell bodies, and mean pixel density of the selections was then recorded.

To verify the specificity of the antibodies used, full-length NGF, BDNF, and NT-3 cDNAs subcloned in a cytomegalovirus early gene promoter expression vector were expressed in HEK293 cells. Immunoreactivity for the anti-BDNF antibody used was detected only in BDNFtransfected cells, and immunoreactivity for the anti-NT-3 antibody used was detected only in NT-3-transfected cells (data not shown).

In situ hybridization. A 454 bp Pst I-SphI fragment of BDNF, corresponding to the C-terminal 52 residues and $297 \mathrm{bp}$ of $3^{\prime}$ untranslated sequence, and a $475 \mathrm{bp}$ EcoRI-HhaI fragment of NT-3, corresponding to residues $81-239$, were subcloned into the vector pT7/T3 $\alpha-19$ (Ambion, Austin, TX), which flanks the inserts with $\mathrm{T} 7$ and $\mathrm{T} 3$ promoters. Digoxigenin-UTP (Boehringer Mannheim)-labeled sense and antisense cRNA probes were then prepared using T3 and T7 RNA polymerases. Probes were quantified by dot blot comparison with control digoxigeninlabeled RNA and stored in $50 \%$ formamide at $-80^{\circ} \mathrm{C}$ until used.

Dissociated spiral ganglia cultures, cultured for $24 \mathrm{hr}$ on polyornithineand laminin-treated glass slides as above, were fixed with fresh $4 \%$ paraformaldehyde for $20 \mathrm{~min}$ at room temperature. The slides were washed three times with PBS and treated with predigested proteinase $\mathrm{K}$ (20 $\mu \mathrm{g} / \mathrm{ml}$; Boehringer Mannheim) for $20 \mathrm{~min}$ at $37^{\circ} \mathrm{C}$. The slides were then fixed again for $10 \mathrm{~min}$ at room temperature, followed by two washes with PBS and one wash in water. The slides were then acetylated with $0.25 \%(\mathrm{v} / \mathrm{v})$ acetic anhydride in $10 \mathrm{~mm}$ triethanolamine- $\mathrm{HCl}$ for $10 \mathrm{~min}$ at room temperature, washed once in water, and dehydrated through an ethanol gradient $(50 \%-70 \%-90 \%-95 \%-100 \%-100 \%)$. Slides not used immediately for in situ hybridization were stored at $-80^{\circ} \mathrm{C}$ until needed (no longer than 2 weeks)

Slides were prehybridized with hybridization buffer $(50 \%$ deionized formamide, $5 \times$ Denhardt's solution, $5 \times \mathrm{SSC}, 1 \% \mathrm{SDS}, 50 \mu \mathrm{g} / \mathrm{ml}$ heparin, $0.5 \mathrm{mg} / \mathrm{ml}$ heat-denatured herring sperm DNA, and $0.25 \mathrm{mg} / \mathrm{ml}$ yeast tRNA) for $1 \mathrm{hr}$ at $48^{\circ} \mathrm{C}$. Sense and antisense BDNF and NT-3 cRNA probes at concentrations of $100 \mathrm{ng} / \mathrm{ml}$ in hybridization buffer were hybridized at $48^{\circ} \mathrm{C}$ overnight. After hybridization, the coverslips were soaked off in $2 \times$ SSC. The slides were then treated with a combination of RNase A $(2 \mu \mathrm{g} / \mathrm{ml})$ and RNase $\mathrm{T}_{1}(1 \mathrm{U} / \mathrm{ml})$ (both from Boehringer Mannheim) for $20 \mathrm{~min}$ at $37^{\circ} \mathrm{C}$ to remove nonhybridized probe. Posthybridization washes consisted of the following: $2 \times$ SSC, $15 \mathrm{~min}$ at room temperature; $1 \times$ SSC, $15 \mathrm{~min}$ at room temperature; and $0.5 \times \mathrm{SSC}, 1 \mathrm{hr}$ at $48^{\circ} \mathrm{C}$. The slides were then incubated for $2 \mathrm{hr}$ at room temperature with anti-digoxigenin Fab fragment (Boehringer Mannheim), diluted 1:500 in blocking buffer, followed by three washes in $0.2 \%$ Triton X-100 in PBS. Slides were then treated with 5-bromo-4-chloro-3-indolylphosphate-nitroblue tetrazoliumchloride (BCIP/NBT) chromogen. Color development was monitored visually, and the reaction was stopped by rinsing the slides in PBS. Neurons were identified by immunofluorescence using anti-NF200 monoclonal antibody as above.

Reagents and culture medium. Dissociated spiral ganglion cell cultures were maintained in a serum-free culture medium consisting of highglucose $(4.5 \mathrm{mg} / \mathrm{ml})$ DMEM with $0.1 \mathrm{mg} / \mathrm{ml}$ penicillin and $0.1 \mathrm{mg} / \mathrm{ml}$ streptomycin, in addition to a serum-free supplementation, a modification of the N2 formulation (Bottenstein and Sato, 1979). Our supplementation consisted of the following: human apo-transferrin $(100 \mu \mathrm{g} / \mathrm{ml})$, putrescine $(100 \mu \mathrm{M})$, progesterone $(20 \mathrm{nM})$, selenium $(30 \mathrm{nM})$, crystalline BSA $(20 \mu \mathrm{g} / \mathrm{ml})$, and D-glucose $(1.5 \mathrm{mg} / \mathrm{ml}$; to a final glucose concentration of $6 \mathrm{mg} / \mathrm{ml}$ in the culture medium). Stocks $(100 \times)$ were prepared and kept at $-80^{\circ}$. Fresh insulin $(10 \mu \mathrm{g} / \mathrm{ml})$ was added to the supplemental medium on the day of culture. DMEM was prepared in the Diabetes and Endocrinology Research Core facility at the University of Iowa, and all of the medium supplements were purchased from Sigma.

Trk-IgG fusion proteins, recombinant human NT-3, NT-3 and BDNF cDNAs, and some of the anti-NT-3 and anti-BDNF antibodies used were generously provided by Genentech. NGF was purified from mouse salivary glands as described previously (Mobley et al., 1972). PD98059 was a generous gift of Dr. Alan Saltiel (Parke-Davis, Ann Arbor, MI). BDNF was purchased from Promega; KN-62, Rp-cAMPS, and LY294002 were purchased from Calbiochem (San Diego, CA). Rp-adenosine-3', 5'cyclic-phosphorothioate (Rp-cAMPS) was kept as a $10 \mathrm{~mm}(10 \times)$ stock dissolved in culture media; PD98059 and LY294002 were kept, respectively, as a $0.2 \mathrm{M}(10,000 \times)$ stock and a $0.1 \mathrm{M}(5000 \times)$ stock dissolved in DMSO. DMSO alone had no effect on survival at the concentration used. Other biochemicals were from Sigma, and buffer reagents were from Fisher Scientific (Houston, TX) unless otherwise specified.

\section{RESULTS}

\section{Endogenous synthesis and release of neurotrophins contribute to the survival-promoting effect of membrane depolarization}

Previous studies have shown that electrical activity or depolarization upregulates BDNF expression in certain CNS neurons in vivo (Zafra et al., 1990, 1992; Isackson et al., 1991; Gall, 1992; Lindholm et al., 1994) and in vitro (Zafra et al., 1990, 1992; Elliott et al., 1994; Ghosh et al., 1994). This can account for the survivalpromoting effect of depolarization via an autocrine neurotrophic mechanism (Ghosh et al., 1994). Having shown previously that depolarization is an effective survival-promoting stimulus for SGNs (Hegarty et al., 1997), we sought to determine whether endogenous neurotrophin synthesis is involved. Because mammalian SGNs are supported in vivo (Ernfors et al., 1996; Staecker et al., 1996) and in vitro (Lefebvre et al., 1994; Pirvola et al., 1994; Zheng et al., 1995; Hegarty et al., 1997) by both BDNF and NT-3, we assessed the requirement for these neurotrophins for survival of cultured SGNs in depolarizing medium. Depolarizing medium contained $30 \mathrm{~K}$ as opposed to the normal $5.4 \mathrm{~mm} \mathrm{~K}^{+}(5 \mathrm{~K})$. We used TrkB-IgG and TrkC-IgG fusion "immunoadhesin" proteins (Shelton et al., 1995) to block the trophic effects of BDNF and NT-3. These proteins consist of the extracellular ligand binding domain of a Trk fused to the Fc domain of a human IgG. A Trk-IgG protein binds neurotrophins with affinities and specificities comparable with those of the Trk receptor from which it was derived. When applied to neurons, including SGNs, Trk-IgGs compete with the homologous endogenous Trks and so block neurotrophin function effectively and with great specificity (Shelton et al., 1995; Zheng et al., 1995).

To test the requirement for BDNF and NT-3 in the action of trophic stimuli, we added TrkB-IgG or TrkC-IgG at $1 \mu \mathrm{g} / \mathrm{ml}$ to spiral ganglion cultures maintained in BDNF, NT-3, 30K, or the permeant cAMP analog cpt-cAMP. Surviving neurons were fixed, stained, and counted $48 \mathrm{hr}$ later. The results are presented in Figure 1. As expected, TrkB-IgG completely inhibited the survival-promoting effect of BDNF on SGNs and partially inhibited the survival-promoting effect of NT-3. The inhibition of NT-3 was probably attributable to the ability of NT-3 to bind TrkA and TrkB, albeit at lower affinity than to TrkC (Bothwell, 1995). TrkC-IgG completely inhibited the survival-promoting effect of NT-3 on SGNs with no effect on that of BDNF. TrkBIgG or TrkC-IgG, either singly or in combination, inhibited SGN survival in $30 \mathrm{~K}$ but did not do so completely. The number of neurons surviving at $48 \mathrm{hr}$ in $30 \mathrm{~K}$ was reduced by less than half with Trk-IgGs added at concentrations that completely block the trophic effects of exogenous neurotrophins. These data imply that endogenous synthesis and release of neurotrophins by SGNs constitutes an autocrine mechanism that contributes to SGN survival under depolarizing conditions. Both NT-3 and BDNF appear to be necessary for effectiveness of this autocrine neurotrophic signaling pathway. 


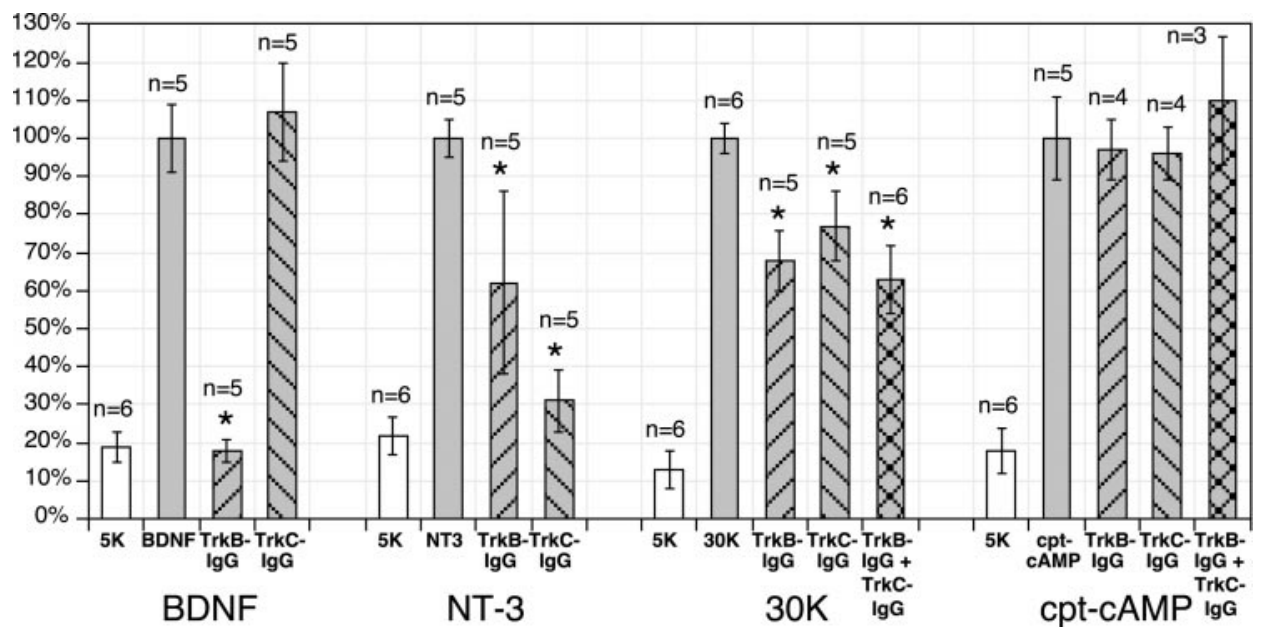

Figure 1. Trk-IgG immunoadhesins abolish the survival-promoting effect of the cognate neurotrophins but only partially inhibit the survival-promoting effect of depolarization. Spiral ganglion cultures were maintained for $48 \mathrm{hr}$ in control medium, which is DMEM plus N2 (5K), or in DMEM plus N2 with one of the following trophic stimuli: BDNF $(50 \mathrm{ng} / \mathrm{ml}), \mathrm{NT}-3(50 \mathrm{ng} / \mathrm{ml}), 30 \mathrm{~K}$, or $1 \mathrm{mM} \mathrm{cpt}-\mathrm{cAMP}$, each stimulus with or without $1 \mu \mathrm{g} / \mathrm{ml}$ TrkB-IgG or TrkC-IgG. SGN survival was determined by counting NSE-positive neurons. Survival is expressed as a percentage of the number of SGNs in each individual trophic condition without Trk-IgG. Maximal survival was obtained in the 30K condition, as described previously (Hegarty et al., 1997). As noted in Materials and Methods, this was $\sim 25 \%$ of the neurons plated. Survival in neurotrophins was less than in 30K, as shown in Figures 5 and 6 and by Hegarty et al. (1997). This figure and Figures 5-7 show the mean \pm SD (error bars) values for all of the determinations performed for each condition. The number of separate determinations for each condition is shown above each bar. Each determination was done in triplicate. For each Trk-IgGcontaining condition labeled with an asterisk, Trk-IgG inclusion reduced survival significantly relative to the same condition without Trk-IgG, as determined by Student's $t$ test ( $p<0.005$ for all comparisons).

Trk-IgGs had no significant effect on SGN survival attributable to the permeant cAMP analog cpt-cAMP (Fig. 1). This implies that cAMP-dependent trophic signaling in SGNs does not involve an autocrine mechanism using neurotrophins.

\section{BDNF and NT-3 are expressed by spiral ganglion neurons in vitro}

The data above imply that BDNF and NT-3 are both synthesized and released by cells in the culture, by either the neurons or the non-neuronal cells. To verify NT-3 and BDNF synthesis and determine which cells are responsible, we used both in situ hybridization and immunocytochemistry.

BDNF and NT-3 mRNAs were assessed by in situ hybridization using digoxigenin-labeled antisense cRNA probes for either BDNF or NT-3. Neurons in the cultures were identified by immunocytochemistry using an anti-NF200 antibody and FITCconjugated secondary antibody. As shown in Figure 2, SGNs expressed both NT-3 and BDNF mRNAs in vitro. Nearly all of the neurons expressed BDNF and NT-3 in the separate assessments of these neurotrophins. On this basis, we conclude that BDNF and NT-3 are primarily coexpressed in SGNs. To the extent that it can be determined by in situ hybridization, expression of BDNF and NT-3 appeared to be primarily restricted to the neurons in the culture. However, we cannot rule out the possibility that neurotrophins are expressed at low levels in the non-neuronal cells.

For immunocytochemical detection, spiral ganglion cultures were fixed $24 \mathrm{hr}$ after plating and probed with rabbit anti-NT-3 or rabbit anti-BDNF antibodies and mouse anti-NF-200 antibodies to detect neurotrophins and to simultaneously identify neurons. tetramethylrhodamine isothiocyanate (TRITC)- and FITCconjugated secondary antibodies were used to visualize the neurotrophin and NF-200 labels, respectively. Both NT-3 (Fig. 3B) and BDNF (Fig. 3D) proteins were present in SGNs maintained in depolarizing medium $(30 \mathrm{~K})$. To the extent that it can be determined by immunocytochemistry, BDNF and NT-3 expres-
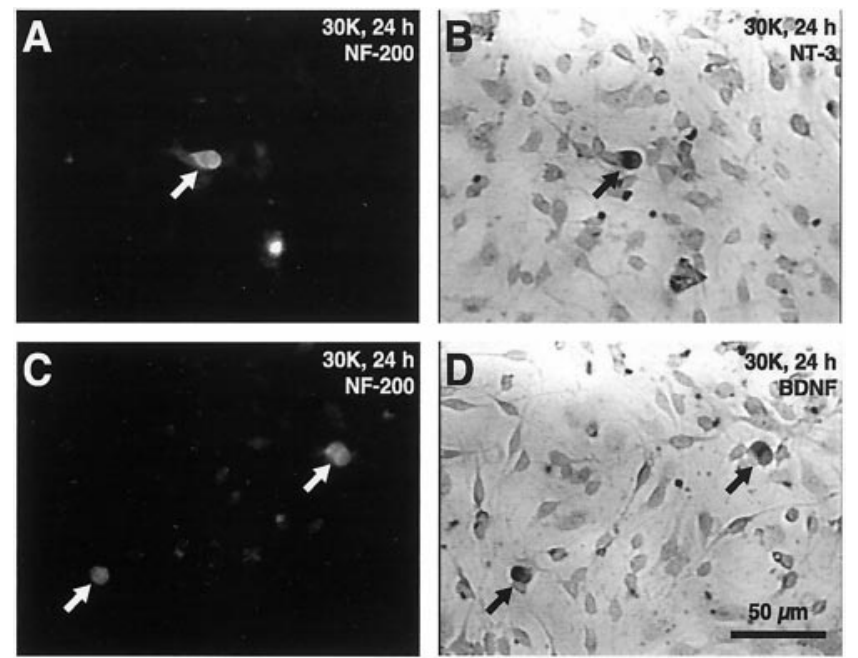

Figure 2. Spiral ganglion neurons express BDNF and NT-3 mRNA in basal or depolarizing medium. Spiral ganglion cultures were maintained for $24 \mathrm{hr}$ in $30 \mathrm{~K}$. In situ hybridization was performed with digoxigeninUTP-labeled antisense cRNA probes for NT-3 $(B)$ or BDNF $(D)$. Hybridized probe was visualized with HRP-conjugated anti-digoxigenin Fab fragment, followed by BCIP-NBT substrate. Control hybridizations with sense cRNA showed no labeling of the cultures (data not shown). Neurons were identified by immunocytochemistry staining with anti-NF-200 primary antibodies and TRITC-conjugated secondary antibodies. The slides were photographed with fluorescence microscopy to detect the antiNF-200 (left panels) and with bright-field microscopy to detect the BCIP-NBT staining (right panels). Neurons (NF-200-positive cells) are indicated by arrows in the left panels $(A, C)$, with the arrows indicating identical positions in the corresponding bright-field images $(B, D)$. Scale bar, $50 \mu \mathrm{m}$.

sion were primarily restricted to the neurons in the culture. The level of neurotrophin expression varied among the neurons, particularly in $30 \mathrm{~K}$.

Spiral ganglion neurons die rapidly when maintained in control 

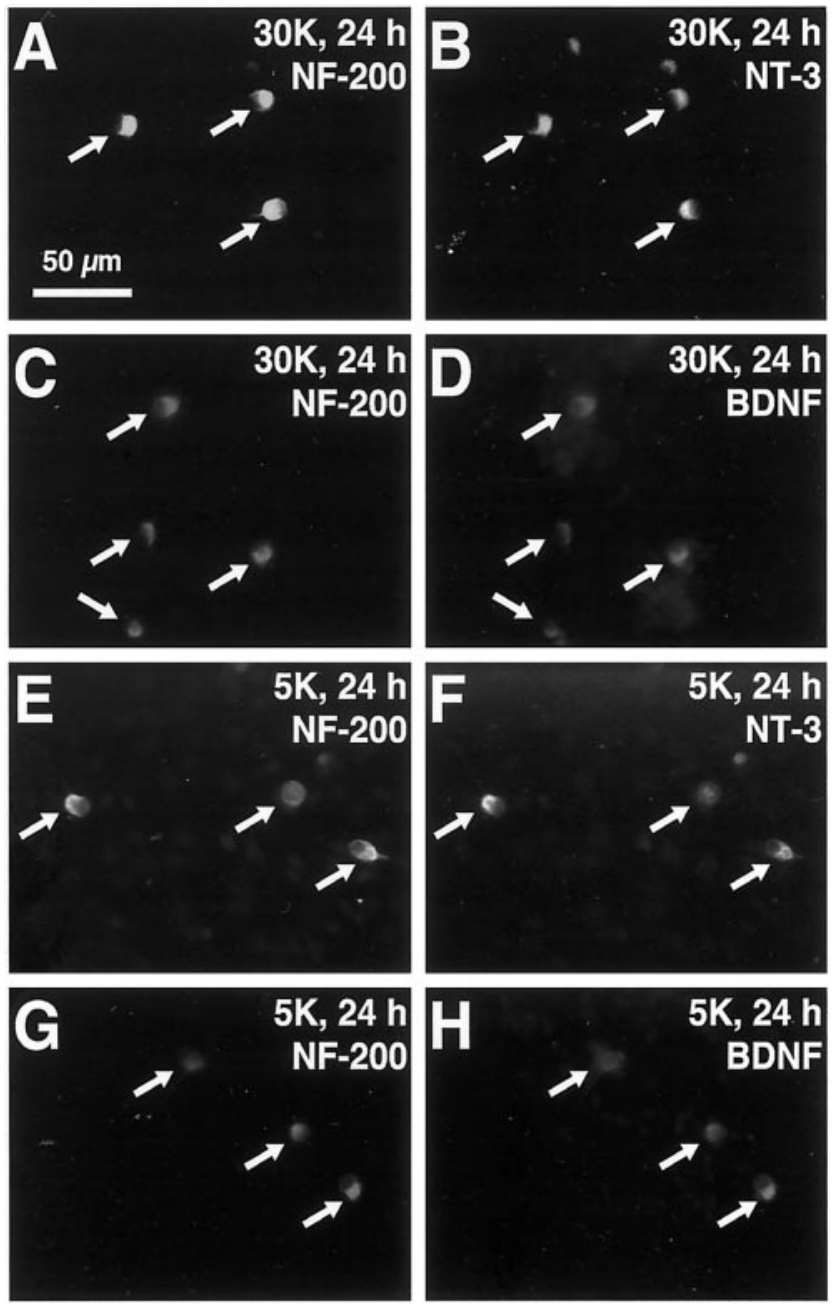

Figure 3. Spiral ganglion neurons express BDNF and NT-3 protein in basal or depolarizing medium. Spiral ganglion cultures were maintained for $24 \mathrm{hr}$ in $5 \mathrm{~K}$ or $30 \mathrm{~K}$. NF-200 protein was detected with a mouse monoclonal antibody and FITC-conjugated secondary antibody. NT-3 (B, $F)$ or $\operatorname{BDNF}(D, H)$ proteins were detected with a rabbit polyclonal antibody and TRITC-conjugated secondary antibody. Neurons were located with an FITC filter set and then photographed sequentially with FITC and TRITC filter sets. FITC fluorescence is shown in the left panels, with the corresponding TRITC image to the right. Neurons (FITC-labeled, NF-200-positive cells) are indicated by arrows in the left panels, with the arrows indicating identical positions in the corresponding TRITC images on the right. $A-D$, SGNs in $30 \mathrm{~K}$. $E-H$, SGNs in control $5 \mathrm{~K}$ medium. Scale bar, $50 \mu \mathrm{m}$.

$5 \mathrm{~K}$ medium, but those neurons that do survive for up to $24 \mathrm{hr}$ in $5 \mathrm{~K}(\sim 50 \%$ of those in $30 \mathrm{~K}$ at $24 \mathrm{hr})$ continue to express both NT-3 (Fig. $3 F$ ) and BDNF (Fig. $3 H$ ). A small number of SGNs survive up to $48 \mathrm{hr}$ in $5 \mathrm{~K}$ medium $(\sim 15 \%$ of those in $30 \mathrm{~K}$ at 48 $\mathrm{hr}$ ) and continue to express BDNF and NT-3 (data not shown). These data indicate that depolarization is not necessary for maintenance of neurotrophin expression in cultured SGNs, although it may cause a small increase in BDNF expression (Fig. 4). That depolarization is not necessary for neurotrophin expression in SGNs is consistent with observation of neurotrophin expression in SGNs in vivo and from postnatal day 5 rats within $4 \mathrm{hr}$ of culture (M. R. Hansen, X.-M. Zha, and S. H. Green, unpublished observations), despite the fact that electrical activity does not appear in rat SGNs until at least the ninth postnatal day (Rübsamen and Lippe, 1998). Mou et al. (1997) have demonstrated
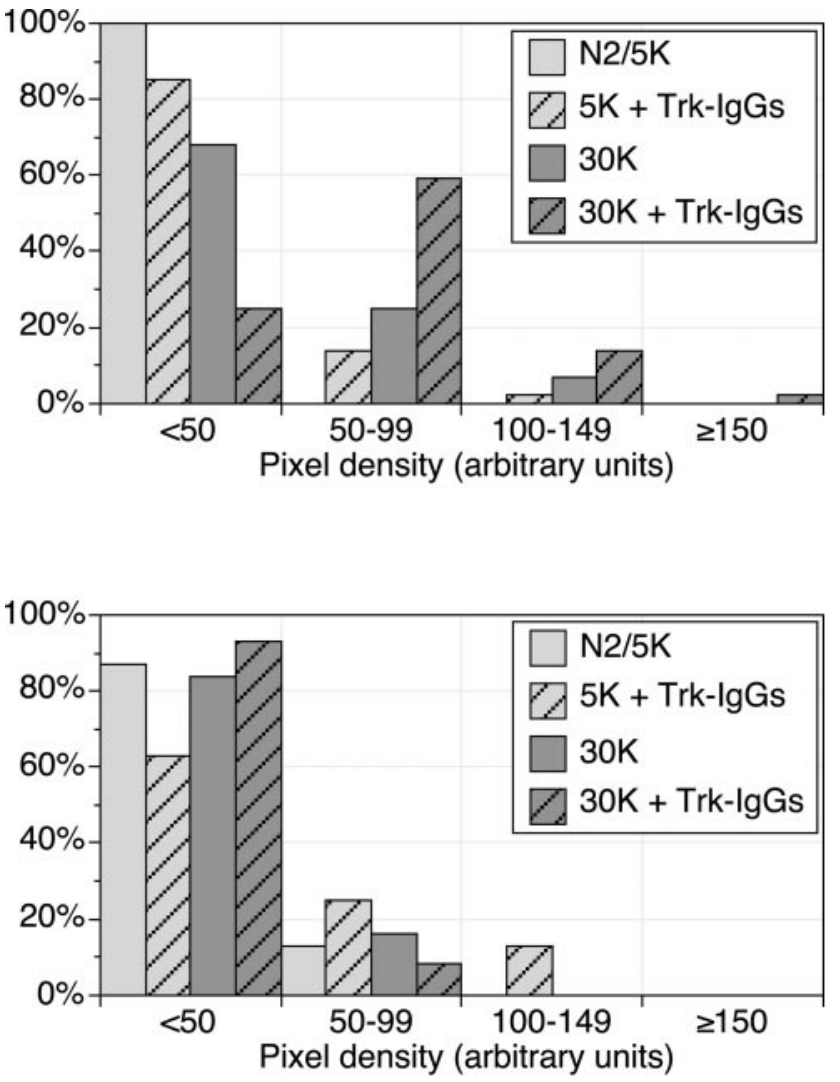

Figure 4. Quantitation of BDNF and NT-3 immunofluorescence. Spiral ganglion cultures were maintained for $24 \mathrm{hr}$ in $5 \mathrm{~K}$ or $30 \mathrm{~K}$ in the presence or absence of Trk-IgGs $(1 \mu \mathrm{g} / \mathrm{ml}$ TrkB-IgG plus $1 \mu \mathrm{g} / \mathrm{ml}$ TrkC-IgG). NF-200, BDNF, and NT-3 were visualized by immunofluorescence as for Figure 3. The neurons were identified by NF-200 immunoreactivity, and the approximate level of immunofluorescence was quantified using digitized images as described in Materials and Methods using NIH Image. The intensity scale was arbitrary but identical for all experiments. All of the neurons exhibited fluorescence greater than background. The neurons were assigned to four classes of fluorescence intensity based on their appearance: low (0-49), medium (50-99), high (100-149), or (rarely) very high $(\geq 150)$ intensity. Significance of differences in immunofluorescence intensity values among the conditions was determined by using $\chi^{2}$ values. For BDNF, shift from depolarizing (30K) to nondepolarizing (5K) medium resulted in a significant change in BDNF immunoreactivity, independently of any effects of Trk-IgGs. Also, addition of Trk-IgGs resulted in a statistically significant increase in BDNF immunoreactivity, independently of any effect of depolarization. For NT-3, there was no statistically significant change attributable to depolarization or to TrkIgGs independently.

previously Trk expression by cultured SGNs, and we do not detect a significant difference in Trk levels between depolarized and nondepolarized SGNs (data not shown).

An alternative explanation of the data might be that a subpopulation of the SGNs loses neurotrophin expression in the absence of depolarization but that these cells die. We would therefore not detect those SGNs that curtail neurotrophin expression in $5 \mathrm{~K}$ because they would have disappeared before assay. However, it is difficult to reconcile this explanation with the observation that a complete blockade of neurotrophin signaling (Fig. 1; see below) spares the majority of SGNs in $30 \mathrm{~K}$, whereas the majority of SGNs die in the absence of depolarization. If reduced autocrineparacrine neurotrophin signaling dooms an SGN to die, then treatment with Trk-IgGs would be expected to cause the majority of SGNs in $30 \mathrm{~K}$ to die. 
Immunofluorescence in images such as those of Figure 3 was quantified using NIH Image, as described in Materials and Methods, to determine the extent to which neurotrophin expression changed in response to the experimental manipulations above. In particular, we considered the possibility that Trk-IgGs, which prevent the survival of only a fraction of the SGNs in $30 \mathrm{~K}$, are selectively jeopardizing those neurons that are expressing higher levels of neurotrophins. These might represent a subpopulation of SGNs that is more dependent on the autocrine mechanism. Alternatively, the SGN population might be fairly homogenous with regard to dependence on the autocrine mechanism, so neurons with lower levels of neurotrophin expression would be as, or more, susceptible to blockade of the autocrine pathway by Trk-IgGs.

Our quantitation of immunofluorescence is shown in Figure 4 in the form of histograms of the number of cells exhibiting different levels of BDNF or NT-3 immunoreactivity. Because the neurotrophin immunofluorescence was relatively low (for comparison, the NF-200 immunofluorescence in Fig. $3 A, C, E, G$ was 225-250 units) and the images varied in contrast, we felt that the neurons could be assigned with confidence to classes of low $(<50)$, medium (50-99), high (100-149), or very high $(\geq 150)$ levels of pixel density but that finer distinctions could not be made with confidence.

In nondepolarizing $5 \mathrm{~K}$ medium, SGNs exhibit BDNF immunofluorescence (Fig. 4A). After $24 \mathrm{hr}$ in $30 \mathrm{~K}$, a fraction of the neurons exhibited a small, but significant, increase in the level of BDNF immunofluorescence (Fig. 4A). We infer that, in SGNs, depolarization is not necessary for BDNF expression and does not strongly induce BDNF expression. The increase that was observed may be attributable to induction by depolarization or may be attributable to preferential loss of neurons expressing lower levels of BDNF. NT-3 immunofluorescence, also present in SGNs in 5K, was not significantly increased by maintenance in $30 \mathrm{~K}$.

Our data, shown in Figure 4, indicate that Trk-IgGs do not selectively compromise neurons expressing higher levels of neurotrophins. Rather, in cultures maintained with $1 \mu \mathrm{g} / \mathrm{ml}$ TrkBIgG plus $1 \mu \mathrm{g} / \mathrm{ml}$ TrkC-IgG, there was a small, but significant, increase in the number of SGNs with higher BDNF immunofluorescence levels (Fig. 4A). This was observed in SGNs cultured with Trk-IgGs in either $5 \mathrm{~K}$ or $30 \mathrm{~K}$ medium. This may imply that SGNs expressing lower levels of BDNF are selectively compromised by the Trk-IgGs or that blockade of neurotrophin signaling cause an upregulation of BDNF expression in SGNs.

A small increase in NT-3 immunofluorescence could be detected in the presence of Trk-IgGs (Fig. 4B) but only in SGNs cultured in $5 \mathrm{~K}$. No increase was observed in cells cultured in $30 \mathrm{~K}$. Thus, Trk-IgGs may preferentially compromise survival of SGNs expressing lower levels of NT-3 but do not significantly affect NT-3 expression.

\section{Inhibition of the Ras-ERK signaling pathway reduces spiral ganglion neuron survival in depolarizing conditions by inhibiting the autocrine mechanism}

Membrane depolarization has been shown to activate Ras and, consequently, the ERK-MAP kinase pathway in PC12 cells (Rosen et al., 1994). ERK activity has been implicated in survivalpromoting signaling in PC12 cells (Xia et al., 1995; Yan and Greene, 1998) and neurons (Bonni et al., 1999; Mazzoni et al., 1999). This raises the possibility that membrane depolarization promotes survival via the Ras-ERK pathway. To test this, we blocked signaling through this pathway by using PD98059 (Pang et al., 1995), which inhibits mitogen-activated protein kinase

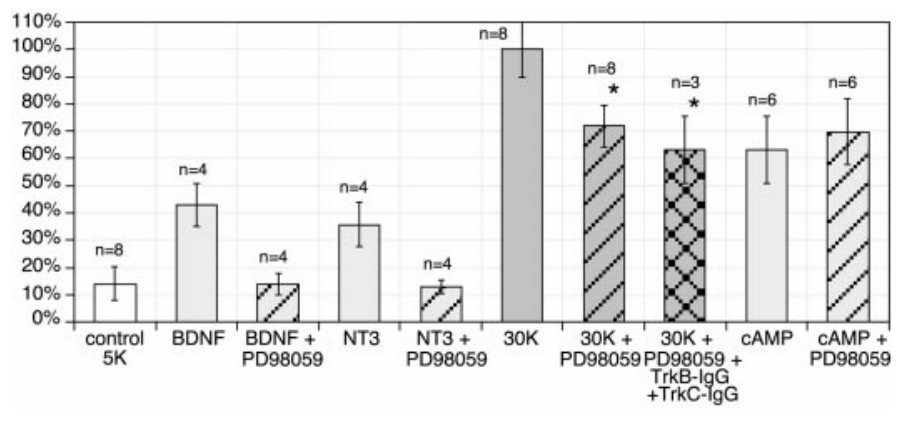

Figure 5. PD98059 abolishes the survival-promoting effect of neurotrophins but only partially inhibits the survival-promoting effect of depolarization. Spiral ganglion cultures were maintained for $48 \mathrm{hr}$ in $5 \mathrm{~K}$ or in DMEM plus N2 with one of the trophic stimuli used in Figure 1, each stimulus with or without $20 \mu \mathrm{M}$ PD98059. In addition, survival was assayed in $30 \mathrm{~K}$ with PD98059 and both TrkB-IgG and TrkC-IgG (each at $1 \mu \mathrm{g} / \mathrm{ml}$ ). Survival was determined as in Figure 1 and is expressed as a percentage of the number of SGNs in the $30 \mathrm{~K}$ condition, the condition with maximal survival. Shown is the mean $\pm \mathrm{SD}$ (error bars) value for all of the determinations performed for each condition. The number of separate determinations for each condition is shown above each bar. Each determination was done in triplicate. Survival in the two conditions containing 30K plus PD98059 (asterisks) is significantly reduced from that in $30 \mathrm{~K}$ alone, as determined by Student's $t$ test $(p<0.01)$, but they are not significantly different from each other.

kinase (MEK), the protein kinase that phosphorylates and activates ERKs. PD98059 at concentrations of $20 \mu \mathrm{M}$ completely prevented ERK phosphorylation, determined by immunocytochemistry using an anti-phospho-ERK antibody (obtained from New England Biolabs, Beverly, MA) (data not shown).

PD98059 $(20 \mu \mathrm{M})$ was added to spiral ganglion cultures maintained in BDNF, NT-3, 30K, or cpt-cAMP. Neuronal survival was assessed as above after $48 \mathrm{hr}$, and the results are presented in Figure 5. PD98059 completely inhibited the survival-promoting effect of neurotrophins on SGNs, implying that neurotrophins require signaling via the ERKs or some other pathway inhibited by PD98059 to promote survival.

Addition of PD98059 partly inhibited the survival-promoting effect of $30 \mathrm{~K}$. One interpretation of this result is that membrane depolarization does promote survival, at least in part, by activating ERK signaling or some other pathway inhibited by PD98059. However, given that PD98059 blocked trophic signaling by neurotrophins, another interpretation is that PD98059 reduces survival in $30 \mathrm{~K}$ by blocking the contribution of the autocrine neurotrophic mechanism to survival in $30 \mathrm{~K}$. This is supported by the observation that PD98059 inhibited SGN survival to approximately the same degree as did the Trk-IgGs (Fig. 1). To distinguish between these two hypotheses, we assessed SGN survival in 30K with PD98059 and both TrkB-IgG and TrkC-IgG (Fig. 5). Inhibition of depolarization-dependent survival by these inhibitors when present in combination was approximately the same as when each was present alone. This lack of additivity supports the hypothesis that PD98059 and Trk-IgGs are blocking the same pathway, implying that the activity inhibited by PD98059 (presumably MEK) lies within the autocrine neurotrophin pathway. If membrane depolarization requires the Ras-ERK pathway to promote survival to any extent, it appears to be indirect because of the contribution of the autocrine mechanism.

PD98059 was without significant effect on SGN survival attributable to cpt-cAMP (Fig. 5). This indicates that promotion of SGN survival by cAMP does not involve intracellular signaling pathways inhibited by PD98059, such as the Ras-ERK pathway, 


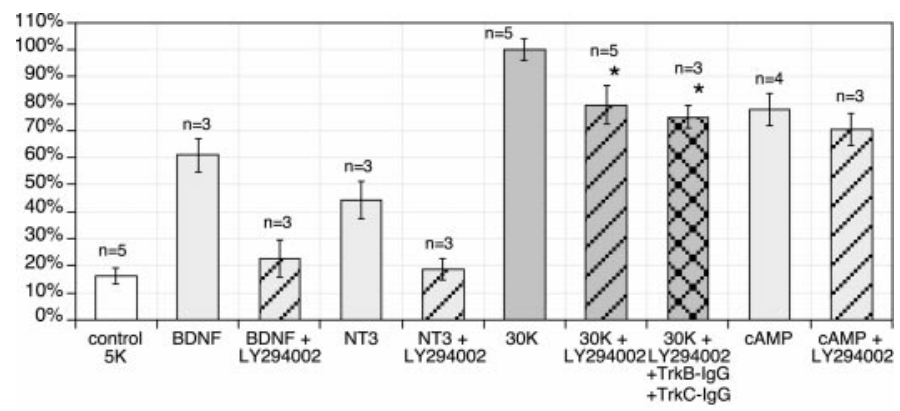

Figure 6. LY294002 abolishes the survival-promoting effect of neurotrophins but only partially inhibits the survival-promoting effect of depolarization. Spiral ganglion cultures were maintained for $48 \mathrm{hr}$ in $5 \mathrm{~K}$ or in DMEM plus N2 with one of the trophic stimuli used in Figure 1, each stimulus with or without $20 \mu \mathrm{M}$ LY294002. In addition, survival was assayed in 30K with LY294002 and TrkB-IgG plus TrkC-IgG (each at 1 $\mu \mathrm{g} / \mathrm{ml}$ ). Survival was determined as in Figure 1 and is expressed as a percentage of the number of SGNs in the $30 \mathrm{~K}$ condition, the condition with maximal survival. Counting, plotting, and statistics are as for Figure 5. Survival in the two conditions containing 30K plus LY294002 (asterisks) is significantly reduced from that in $30 \mathrm{~K}$ alone, as determined by Student's $t$ test $(p<0.01)$, but they are not significantly different from each other.

either directly or indirectly. Moreover, the lack of effect of PD98059 on SGN survival rules out any potential nonspecific toxic effects of the drug.

\section{Inhibition of the phosphatidylinositol-3-OH kinase-PKB pathway reduces SGN survival in depolarizing conditions by affecting the autocrine mechanism}

The PI3K-PKB pathway is critically important for the survivalpromoting effect of peptide neurotrophic factors (Yao and Cooper, 1995; D’Mello et al., 1997; Dudek et al., 1997; Miller et al., 1997) and has been implicated as a mediator of the survival-promoting effects of depolarization (Miller et al., 1997; Vaillant et al., 1999). We therefore assessed the requirement for the PI3K-PKB pathway for survival attributable to depolarization alone or survival attributable to the autocrine neurotrophic mechanism.

The PI3K inhibitor LY294002 $(20 \mu \mathrm{M})$ was added to spiral ganglion cultures maintained in BDNF, NT-3, 30K, or cpt-cAMP. Neuronal survival was assessed as above after $48 \mathrm{hr}$, and the results are presented in Figure 6. LY294002 completely inhibited the survival-promoting effect of neurotrophins on SGNs, consistent with previous studies demonstrating a requirement for PI3K for the survival-promoting effect of peptide neurotrophic factors.

As was the case for PD98059, addition of LY294002 partly inhibited the survival-promoting effect of $30 \mathrm{~K}$, and this appeared to be attributable to a requirement for PI3K activity for the autocrine neurotrophic mechanism rather than directly in intracellular signaling attributable to depolarization. Again, the evidence for this was that inhibition of survival in 30K by LY294002 alone (Fig. 6) was nearly as great as inhibition by Trk-IgGs (Fig. 1) and that inhibition by LY294002 in combination with Trk-IgGs was approximately the same as by either alone, implying that they inhibit the same pathway.

LY294002 was without significant effect on SGN survival attributable to cpt-cAMP (Fig. 6). This indicates that promotion of SGN survival by cAMP does not involve PI3K, either directly or indirectly. Moreover, the lack of effect of LY294002 on SGN survival rules out any potential nonspecific toxic effects of the drug.

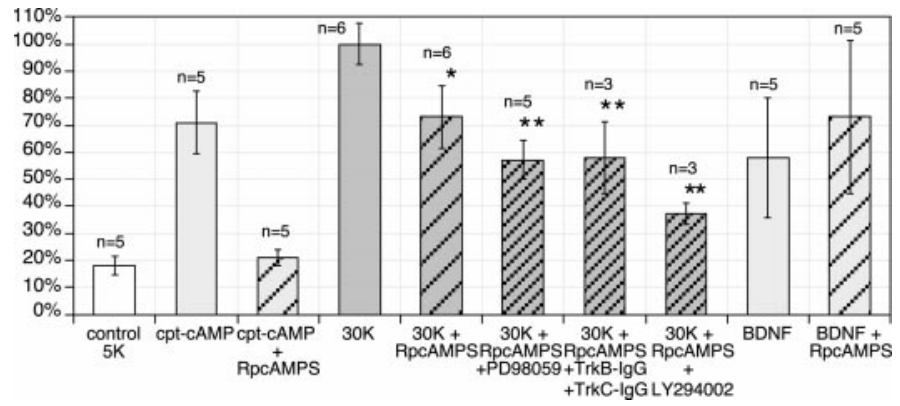

Figure 7. Rp-cAMPS abolishes the survival-promoting effect of cpt-cAMP but only partially inhibits the survival-promoting effect of depolarization. Spiral ganglion cultures were maintained for $48 \mathrm{hr}$ in $5 \mathrm{~K}$ or in DMEM plus N2 with one of the trophic stimuli used in Figure 5, each stimulus with or without $1 \mathrm{~mm}$ Rp-cAMPS. In addition, survival was assayed in $30 \mathrm{~K}$ with Rp-cAMPS and either $20 \mu \mathrm{M}$ PD98059 or $20 \mu \mathrm{M}$ LY294002, or TrkB-IgG plus TrkC-IgG (each at $1 \mu \mathrm{g} / \mathrm{ml}$ ). Survival was determined as in Figure 1 and is expressed as a percentage of the number of SGNs in the $30 \mathrm{~K}$ condition, the condition with maximal survival. Counting, plotting, and statistics are as for Figure 5. Survival in $30 \mathrm{~K}$ plus Rp-cAMPS (single asterisk) is significantly lower than in $30 \mathrm{~K}$, as determined by two-tailed Student's $t$ test $(p=0.002)$. The three conditions labeled with double asterisks are all significantly lower than the $30 \mathrm{~K}$ plus Rp-cAMPS condition, as determined by two-tailed Student's $t$ test $(p<0.04)$.

\section{Promotion of SGN survival by membrane depolarization depends, in part, on signaling via cAMP}

We reported previously that survival of SGNs depolarized by $30 \mathrm{~K}$ exceeds that of SGNs cultured with neurotrophins (Hegarty et al., 1997). This is consistent with the observation above that an autocrine mechanism involving neurotrophins accounts for a fraction of the survival-promoting effect of membrane depolarization, but depolarization must involve additional mechanisms to account for its full survival-promoting effect. In retinal ganglion cells, a signal pathway involving cAMP is involved in the survival-promoting effect of depolarization (Meyer-Franke et al., 1995). Because the permeant cAMP analog cpt-cAMP promotes SGN survival (Hegarty et al., 1997), we asked whether a cAMPdependent pathway could contribute to the survival-promoting effect of membrane depolarization. To block cAMP-dependent signaling, we used the specific cAMP antagonist Rp-cAMPS (Rothermel et al., 1983).

Rp-cAMPS was added at a concentration of $1 \mathrm{~mm}$ to spiral ganglion cultures maintained in BDNF, NT-3, 30K, or cptcAMP. Neuronal survival was assessed after $48 \mathrm{hr}$ as in the preceding experiments, and the results are presented in Figure 7. As expected, Rp-cAMPS completely inhibited the survivalpromoting effect of cpt-cAMP, indicating that it is an effective cAMP antagonist in these neurons. Rp-cAMPS did not reduce SGN survival attributable to neurotrophins, indicating that trophic signaling by neurotrophins does not involve cAMP, consistent with previous observations (Rydel and Greene, 1988). However, Rp-cAMPS did reduce SGN survival in $30 \mathrm{~K}$, but did not do so completely. Thus, recruitment of a cAMP-dependent pathway by membrane depolarization accounts, in part, for the survivalpromoting effect of depolarization.

Because neurotrophins do not require cAMP to promote survival, nor does cpt-cAMP require neurotrophin signaling, we hypothesized that membrane depolarization promotes survival by recruiting these pathways independently. To test this, we assessed SGN survival in $30 \mathrm{~K}$ with Rp-cAMPS in combination with either PD98059 or Trk-IgGs to simultaneously block both cAMP and autocrine neurotrophic mechanisms. Rp-cAMPS, in 


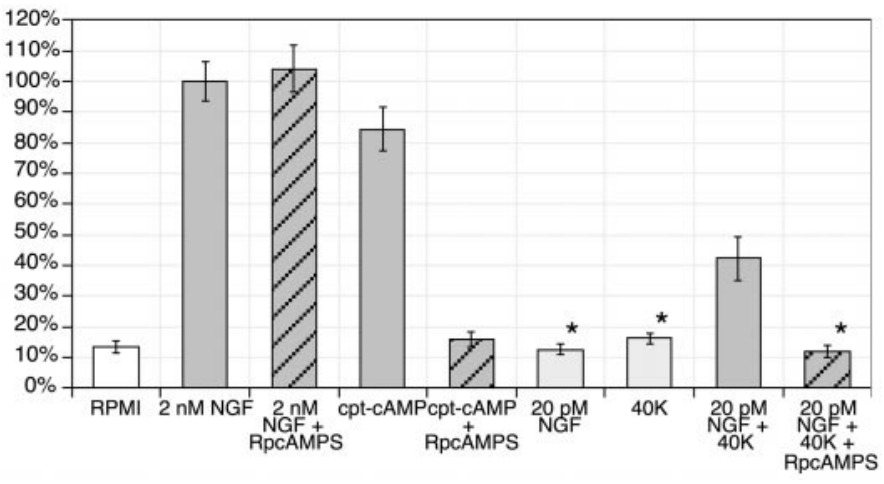

Figure 8. Rp-cAMPS abolishes the survival-promoting effect of depolarization on PC12 cells cultured in low levels of NGF. PC12 cells were maintained for $48 \mathrm{hr}$ in RPMI 1640 medium with no additives or in RPMI 1640 containing one of the following trophic conditions: $2 \mathrm{nM} \mathrm{NGF}, 0.5$ mM cpt-cAMP, 20 pM NGF, 40K, or 20 pM NGF plus 40K; 2 nм NGF, 0.5 mM cpt-cAMP, and 20 pM NGF plus $40 \mathrm{~K}$ were also added in combination with $1 \mathrm{~mm}$ Rp-cAMPS. Survival was determined by counting cells as described in Materials and Methods and is expressed as a percentage of the number of SGNs in $2 \mathrm{~nm} \mathrm{NGF}$, the condition with maximal survival. Data shown are from a single experiment of three repetitions, each done in quadruplicate and each having similar results. The three conditions labeled with asterisks are all significantly lower than the 20 pM NGF plus $40 \mathrm{~K}$ condition, as determined by two-tailed Student's $t$ test $(p<0.001)$.

combination with either PD98059 or Trk-IgGs, inhibited depolarization-dependent survival to a greater degree than did blocking either pathway alone (Fig. 7). This supports a hypothesis that at least two separate signaling pathways are necessary for the survival-promoting effect of depolarization. One is an autocrine neurotrophic mechanism and the other is a cAMP-dependent pathway. Simultaneously blocking both of these pathways does not completely inhibit the survival-promoting effect of membrane depolarization; the number of neurons surviving at $48 \mathrm{hr}$ in $30 \mathrm{~K}$ with the combined inhibitors was nearly half of that in the $30 \mathrm{~K}$ control. This implies that at least one additional survivalpromoting signaling pathway is recruited by membrane depolarization to promote survival.

To determine whether cAMP-dependent signaling might mediate the effects of membrane depolarization more generally, we next assessed this mechanism in PC12 cells. Although membrane depolarization alone neither induces neurite outgrowth nor promotes survival in PC12 cells (Rukenstein et al., 1991), membrane depolarization in combination with epidermal growth factor (Mark et al., 1995) or NGF at a subthreshold level of 20 pM (Solem et al., 1995) will induce neurite outgrowth. Moreover, in the former case, Mark et al. (1995) provided evidence that the effect of membrane depolarization is mediated by a cAMP pathway. We therefore reasoned that the same might apply to a survival-promoting effect of membrane depolarization. As shown in Figure 8, PC12 cell survival in serum-free RPMI medium was supported by 2 nM NGF $(\sim 50 \mathrm{ng} / \mathrm{ml})$ but not by $20 \mathrm{pm}$ NGF. Depolarization provided by raising $\left[\mathrm{K}^{+}\right]$in the medium to $40 \mathrm{~mm}(40 \mathrm{~K})$ also did not promote survival, consistent with previous observations (Rukenstein et al., 1991). However, if the cells were depolarized by $40 \mathrm{~K}$ in the presence of $20 \mathrm{pm}$ NGF, then survival was increased, although not to the level observed with 2 nM NGF (Fig. 8). Maximal survival under these conditions was obtained with $\left[\mathrm{K}^{+}\right]$of $40 \mathrm{~mm}$ in the medium. Addition of the cAMP antagonist Rp-cAMPS completely abolished the survival-promoting effect of cpt-cAMP, was without effect on survival in $2 \mathrm{nM}$ NGF, and completely abolished the

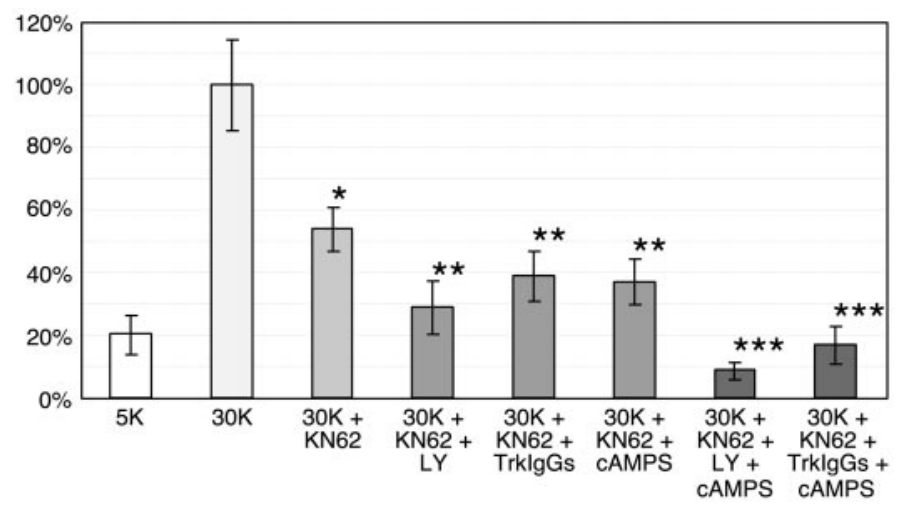

Figure 9. KN-62 partially inhibits the survival-promoting effect of depolarization additive with the effects of LY294002, Trk-IgGs, and RpcAMPS. Spiral ganglion cultures were maintained for $48 \mathrm{hr}$ in $5 \mathrm{~K}$ or in $30 \mathrm{~K}$ or in $30 \mathrm{~K}$ with $1 \mu \mathrm{M} \mathrm{KN}-62(\mathrm{KN} 62)$ alone or in combination with 20 $\mu \mathrm{M}$ LY294002 $(L Y)$ or TrkB-IgG plus TrkC-IgG (each at $1 \mu \mathrm{g} / \mathrm{ml}$ ) (TrkIgGs) or $1 \mathrm{~mm}$ Rp-cAMPS (cAMPS). Survival was determined as in Figure 1 and is expressed as a percentage of the number of SGNs in the $30 \mathrm{~K}$ condition, the condition with maximal survival. Counting, plotting, and statistics are as for Figure 7. Survival in 30K plus KN62 (single asterisk) is significantly ( $p=0.01$ by two-tailed, unpaired Student's $t$ test) lower than in $30 \mathrm{~K}$. The three conditions labeled with double asterisks are all significantly lower than the $30 \mathrm{~K}$ plus $\mathrm{KN}-62$ condition but not from each other. The two conditions labeled with triple asterisks are each significantly different from the corresponding double asterisked condition.

survival-promoting effect of $20 \mathrm{pm}$ NGF plus 40K (Fig. 8). This indicates that, under these conditions, membrane depolarization does recruit cAMP-dependent signaling to mediate its survivalpromoting effect in PC12 cells. In this case, the cAMP-dependent pathway appears to account for the major fraction, if not all, of the survival-promoting effect.

\section{Promotion of SGN survival by membrane depolarization depends, in part, on signaling via $\mathrm{Ca}^{2+} /$ calmodulin-dependent protein kinases}

CaMK activity has been implicated in support of neuronal survival by depolarization (Hack et al., 1993; our unpublished observations). Because inhibition of both cAMP-dependent and Trk-dependent pathways did not completely prevent the ability of depolarization to promote survival, we asked whether CaMKs could provide an additional survival-promoting signaling pathway recruited by membrane depolarization.

Blockade of CaMK signaling with $\mathrm{KN}-62$ has been shown to reduce depolarization-dependent survival of cerebellar granule neurons (Hack et al., 1993) and of SGNs (our unpublished observations), we used KN-62 in combination with inhibitors of cAMP and Trk signaling to determine whether these pathways make independent contributions to the survival-promoting effect of depolarization. The data presented in Figure 9 confirm that KN-62 significantly reduces survival in $30 \mathrm{~K}$. Combining KN-62 with the PI3K inhibitor LY294002 or with Trk-IgGs further reduced survival in $30 \mathrm{~K}$ to a significant degree. A comparable reduction of SGN survival was observed when KN-62 was combined with the cAMP antagonist Rp-cAMPS. Finally, inhibition of all three signaling pathways with a combination of LY294002, Rp-cAMPs, and KN-62 or with a combination of Trk-IgGs, Rp-cAMPS, and KN-62 resulted in a degree of SGN survival no greater than that in culture medium lacking survival-promoting factors. These data suggest that the recruitment of CaMKs by depolarization to promote survival (Hack et al., 1993; our unpublished observations) is independent of and additive with cAMP- and Trk-dependent signaling. 


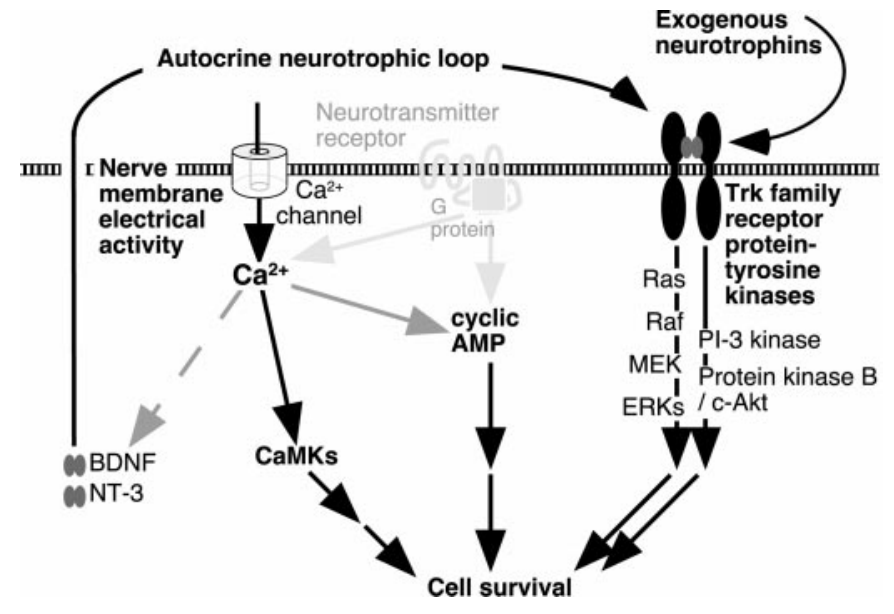

Figure 10. Trophic signaling attributable to depolarization: summary diagram. Depolarization causes $\mathrm{Ca}^{2+}$ entry via L-type $\mathrm{Ca}^{2+}$ channels. Although the increase in $\left[\mathrm{Ca}^{2+}\right]_{\mathrm{i}}$ is necessary for SGN survival in depolarizing conditions, inhibitors of neurotrophin or of cAMP signaling reduce survival. These inhibitors, even in combination, do not completely prevent survival. Therefore, there must be at least one additional trophic signaling pathway, activated by $\mathrm{Ca}^{2+}$, to fully account for the survivalpromoting effect of depolarization. See Discussion for details.

\section{DISCUSSION}

We have investigated the mechanism by which depolarization promotes neuronal survival using SGNs. The key novel result of these studies is that the mechanism is not unitary but, rather, involves at least three distinct mechanisms operating in parallel and additively. Figure 10 summarizes observations reported here and previously regarding trophic support of SGNs. Exogenous neurotrophins promote SGN survival (Avila et al., 1993; Pirvola et al., 1994; Vazquez et al., 1994; Zheng et al., 1995; Hegarty et al., 1997), as does a permeant cAMP analog (Hegarty et al., 1997). Presumably, exogenous neurotrophins, e.g., NT-3 supplied by hair cells, contribute to support of SGNs in vivo. Also, the cAMPdependent survival-promoting signaling pathway could be used by neurotransmitters that increase cytosolic cAMP, as has been observed in retinal ganglion neurons (RGNs) (Kaiser and Lipton, 1990). As has been shown previously for SGNs and other neurons, $\mathrm{Ca}^{2+}$ influx through L-type $\mathrm{Ca}^{2+}$ channels is the first step in trophic signaling by depolarization and is necessary for the trophic effect (Gallo et al., 1987; Collins and Lile, 1989; Koike et al., 1989; Collins et al., 1991; Franklin et al., 1995; Galli et al., 1995; Hegarty et al., 1997). This cooperates with at least three survival signal pathways to achieve maximal neuronal survival. The use of specific blocking reagents, Rp-cAMPS, Trk-IgGs, PD98059, LY294002, and KN-62, allows the identification of these pathways; one is an autocrine neurotrophic mechanism involving BDNF and NT-3, the second is a cAMP-dependent survival-promoting pathway, and the third is a CaMK-dependent pathway. Constitutive autocrine neurotrophic signaling is not sufficient to promote SGN survival in vitro but contributes to survival in depolarizing conditions. The autocrine neurotrophins accomplish their survival-promoting effects via the same intracellular means as used by exogenous neurotrophins and the PI3K-PKB (Yao and Cooper, 1995; D’Mello et al., 1997; Dudek et al., 1997; Miller et al., 1997) and Ras-ERK (Xia et al., 1995) signal pathways.

Spiral ganglion neurons are an advantageous system for study of the mechanisms by which depolarization promotes neuronal survival. SGNs have only a single presynaptic input (the hair cells), which are selectively killed by aminoglycoside antibiotics. Electrical stimulation of such deafferented SGNs through implanted electrodes promotes their survival (Wong-Riley et al., 1981; Lousteau, 1987; Hartshorn et al., 1991; Leake et al., 1991, 1992; Lustig et al., 1994). This is reflected in support of cultured SGNs by depolarization, allowing parallel in vivo and in vitro studies on a single system.

\section{Autocrine neurotrophic signaling in SGNs}

Many CNS and PNS neurons coexpress a neurotrophin and its cognate receptor, suggesting that an autocrine mechanism contributes to survival of the neurons and to neuronal plasticity (Davies, 1996; Lewin and Barde, 1996). SGNs have been shown to express TrkB and TrkC (Ylikoski et al., 1993; Pirvola et al., 1994; Schecterson and Bothwell, 1994; Mou et al., 1997), and we show here that cultured SGNs also express the neurotrophins BDNF and NT-3, which signal through these receptors. We further show that blockade of these receptors reduces SGN survival in vitro in a manner consistent with their involvement in an autocrine mechanism. Membrane electrical activity has been shown to induce neurotrophin expression in a variety of neuronal types, particularly in the CNS (Gall, 1992; Lindholm et al., 1994; Thoenen, 1995). However, the BDNF and NT-3 expression observed in SGNs, although contributing to survival of depolarized SGNs, does not require depolarization.

Comparison of existing studies of neurons in vitro indicates that neurons vary in their requirement for an autocrine pathway for survival. Whereas Ghosh et al. (1994) found that blocking the autocrine pathway completely abolished the trophic effect of depolarization on neocortical neurons, we find that blocking the autocrine pathway only partially inhibited SGN survival in depolarizing conditions. Franklin and Johnson (1994) have reported that an autocrine mechanism does not contribute to survival of sympathetic neurons in depolarizing conditions. Thus, although trophic support by membrane electrical activity is an attribute generally possessed by neurons, these examples illustrate a range of level of involvement of autocrine pathways in the process.

The reduction in SGN survival observed when TrkB-IgG or TrkC-IgG are added to the $30 \mathrm{~K}$ culture medium demonstrates that an autocrine mechanism contributes to the survival of depolarized SGNs, although depolarization is not necessary for neurotrophin synthesis. We suggest that the constitutive synthesis of both BDNF and NT-3 contribute in an additive manner to the survival of depolarized SGNs. We have shown previously additivity in the survival-promoting effects of depolarization and exogenous neurotrophins (Hegarty et al., 1997), consistent with additivity between depolarization and autocrine neurotrophins. SGNs in nondepolarizing medium do synthesize neurotrophins, but survival is nonetheless very low and is not affected by TrkIgGs. Presumably, in the absence of depolarization, the autocrine mechanism alone provides insufficient survival-promoting stimulus to reach a "threshold" level required to suppress cell death.

In the presence of Trk-IgGs, there is a an increase in the fraction of SGNs expressing higher levels of BDNF and NT-3 (Fig. 4). This is consistent with the suggestion above that the autocrine mechanism contributes to the survival-promoting effect of depolarization. Thus, SGNs with the highest levels of endogenous neurotrophin expression would be those least jeopardized by the addition of Trk-IgGs. Also consistent with our observations is the possibility that exposure to Trk-IgGs causes an upregulation of BDNF expression in the SGNs. 


\section{CAMP-dependent neurotrophic signaling in SGNs}

Activation of cAMP signaling provides trophic support to a variety of neurons (Rydel and Greene, 1988; Kaiser and Lipton, 1990; D’Mello et al., 1993; Galli et al., 1995), including SGNs (Hegarty et al., 1997). Elevated $\left[\mathrm{Ca}^{2+}\right]_{\mathrm{i}}$ can cause increased intracellular cAMP, presumably via $\mathrm{Ca}^{2+} / \mathrm{CaM}$-dependent adenylyl cyclase (Cooper et al., 1995). SGNs express $\mathrm{Ca}^{2+} / \mathrm{CaM}$-dependent type I adenylyl cyclase (J. Bok and S. H. Green, unpublished observations) allowing $\mathrm{Ca}^{2+}$ regulation of cAMP in these neurons.

In SGNs, cAMP antagonist partially inhibits promotion of survival by depolarization; in PC12 cells treated with subthreshold levels of NGF, the cAMP antagonist completely inhibits promotion of survival by depolarization. Thus, mediation of depolarization survival signaling by cAMP is likely to be a general phenomenon. However, neurons may vary in their requirement for such mediation by cAMP, just as they do in their requirement for the autocrine pathway mediating the effect of depolarization. For example, cAMP-dependent signaling appears not to be involved in depolarization-promoted survival in cerebellar granule cells (Hack et al., 1993).

In SGNs, cAMP contributes to the survival-promoting effect of depolarization as one of several signaling pathways. In PC12 cells, cAMP is apparently a major mediator of the survival-promoting effect of depolarization. Meyer-Franke et al. (1995) have similarly shown cAMP acting as a mediator of survival-promoting effect of depolarization in RGNs. Our results indicate a different mechanism operating in SGNs. First, in RGNs, neither depolarization nor cAMP elevation alone promote survival, but both strongly potentiate survival in BDNF. Second, unlike what occurs in RGNs, the effect of depolarization is not attributable entirely to cAMP in SGNs. Finally, cAMP appears to potentiate BDNF action in RGNs by causing a translocation of the BDNF receptor TrkB to the plasma membrane (Meyer-Franke et al., 1998), whereas in SGNs, the survival-promoting effect of cAMP is entirely independent of neurotrophins (i.e., not blocked by TrkIgGs, PD98059, or LY294002).

It might be supposed that cAMP promotes survival by directly suppressing the apoptosis machinery, perhaps in a way comparable with that used by peptide neurotrophic factors, e.g., phosphorylation of Bad (Harada et al., 1999). Although this is likely to be important, another means is suggested by the results of Lachica et al. (1995). That study of chick nucleus magnocellularis neurons showed that a CAMP pathway, activated by afferent glutamatergic input, moderates the otherwise potentially cytotoxic increase in $\left[\mathrm{Ca}^{2+}\right]_{\mathrm{i}}$ attributable to glutamate. It is possible that such a mechanism is more general and that cAMP signaling promotes survival in depolarizing conditions by moderating potentially cytotoxic increases in $\left[\mathrm{Ca}^{2+}\right]_{\mathrm{i}}$.

\section{Intracellular signaling pathways recruited by depolarization}

Our data show that trophic signaling by either exogenous or autocrine neurotrophins requires both PI3K-PKB and ERK signaling because blockade of either pathway abolishes the neurotrophin contribution to SGN survival. The PI3K-PKB pathway is well established as crucial for cell survival (Yao and Cooper, 1995; D’Mello et al., 1997; Dudek et al., 1997; Kauffmann-Zeh et al., 1997; Miller et al., 1997; Crowder and Freeman, 1998; Vaillant et al., 1999). However, cells apparently differ in their requirement for the Ras-ERK pathway for survival. In some cases, inhibition of the Ras-ERK pathway does not affect survival (Pang et al., 1995; Yao and Cooper, 1995; Virdee and Tolkovsky, 1996;
Creedon et al., 1997; Miller et al., 1997; Chen et al., 1998; Anderson and Tolkovsky, 1999; Bhave et al., 1999), whereas in others, ERK inhibition compromises cell survival (Xia et al., 1995; Suzuki et al., 1997; Yan and Greene, 1998; Bonni et al., 1999; Erhardt et al., 1999; Mazzoni et al., 1999). As in the latter, SGNs appear to require signaling in both the PI3K and Ras-ERK pathways for promotion of survival by peptide neurotrophic factors. It is unlikely that this is attributable to unintended inhibition of the PI3K-PKB pathway by PD98059; several recent studies have shown that transcriptional and nontranscriptional responses attributable to the PI3K-PKB pathway persist in PD98059treated cells (Dufourny et al., 1997; Chen et al., 1998; Dickens et al., 1998; Su et al., 1998; Wagle et al., 1998; Wang and Sul, 1998).

As discussed above, the PI3K-PKB and/or Ras-ERK pathways are necessary for promotion of survival by factors that signal via protein-tyrosine kinases, e.g., peptide neurotrophic factors. Because $\mathrm{Ca}^{2+}$ can activate protein-tyrosine kinases, e.g., PYK2 (Lev et al., 1995) and/or Src (Rusanescu et al., 1995), it is possible that protein-tyrosine kinase effectors, such as PI3K or ERKs, may participate in depolarization trophic signaling. Indeed, the PI3KPKB pathway has been implicated in promotion of survival by depolarization in some neurons (Miller et al., 1997; Vaillant et al., 1999) but not in others (D’Mello et al., 1997; Dudek et al., 1997). Treatment with PD98059 to block the Ras-ERK pathway or with LY294002 to block the PI3K-PKB pathway reduces SGN survival in $30 \mathrm{~K}$. However, we find that this appears to be attributable entirely to the use of these pathways by the autocrine neurotrophin mechanism. Thus, in SGNs, PI3K and ERKs appear to be required for the survival-promoting effect of neurotrophins but are dispensable for promotion of survival by depolarization, exclusive of the autocrine neurotrophin mechanism.

Simultaneous blockade of both autocrine and cAMP pathways does not completely abrogate the trophic effect of depolarization in SGNs, implying the existence of at least one additional effector. CaMK (Hack et al., 1993; Massé and Kelly, 1997; Vaillant et al., 1999) and CaMK kinase, acting via PKB (Yano et al., 1998), have been implicated in depolarization-dependent survival. CaMKs are activated by depolarization in SGNs, inhibition of CaMK activity compromises depolarization-dependent survival, and CaMK activity is sufficient to support SGN survival in the absence of exogenous survival-promoting factors (our unpublished observations). The data presented here show that recruitment of CaMKs by depolarization is an independent survival-promoting pathway that sums with cAMP and autocrine signaling.

In conclusion, depolarization promotes SGN survival, and our observations show that at least three mechanisms are used to this end. Comparison with other neuronal models suggests that these mechanisms are generally associated with depolarizationdependent neuronal survival. However, the degree to which any one of these mechanisms is used appears to vary substantially among neurons. That multiple mechanisms concomitantly contribute to the survival-promoting effect of depolarization in SGNs may account for the observation that depolarization is a significantly stronger survival-promoting stimulus for cultured SGNs than neurotrophins or cAMP (Hegarty et al., 1997).

\section{REFERENCES}

Anderson CNG, Tolkovsky AM (1999) A role for MAPK/ERK in sympathetic neuron survival: protection against a p53-dependent, JNKindependent induction of apoptosis by cytosine arabinoside. J Neurosci 19:664-673.

Avila MA, Varela-Nieto I, Romero G, Mato JM, Giraldez F, Van De Water TR, Represa J (1993) Brain-derived neurotrophic factor and 
neurotrophin-3 support the survival and neuritogenesis response of developing cochleovestibular ganglion cells. Dev Biol 159:266-275.

Bennett MR, White W (1979) The survival and development of cholinergic neurons in potassium-enriched media. Brain Res 173:549-553.

Bhave SV, Ghoda L, Hoffman PL (1999) Brain-derived neurotrophic factor mediates the anti-apoptotic effect of NMDA in cerebellar granule neurons: signal transduction cascades and site of ethanol action. J Neurosci 19:3277-3286.

Bichler E, Spoendlin H, Rauchegger H (1983) Degeneration of cochlear neurons after amikacin intoxication in the rat. Arch Otorhinolaryngol 237:201-208

Bonni A, Brunet A, West AE, Datta SR, Takasu MA, Greenberg ME (1999) Cell survival promoted by the Ras-MAPK signaling pathway by transcription-dependent and -independent mechanisms. Science 286:1358-1362.

Bothwell M (1995) Functional interactions of neurotrophins and neurotrophin receptors. Annu Rev Neurosci 18:223-253.

Bottenstein JE, Sato G (1979) Growth of a rat neuroblastoma cell line in serum-free supplemented medium. Proc Natl Acad Sci USA 76:514-517.

Catsicas M, Péquinot Y, Clarke PGH (1992) Rapid onset of neuronal death induced by blockade of either axoplasmic transport or action potentials in afferent fibers during brain development. J Neurosci 12:4642-4650.

Chalazonitis A, Fischbach GD (1980) Elevated potassium induces morphological differentiation of dorsal root ganglionic neurons in dissociated cell culture. Dev Biol 78:172-183.

Chen RH, Su YH, Chuang RL, Chang TY (1998) Suppression of transforming growth factor- $\beta$-induced apoptosis through a phosphatidylinositol 3-kinase/Akt-dependent pathway. Oncogene 17:1959-1968.

Collins F, Lile JD (1989). The role of dihydropyridine-sensitive voltage gated calcium channels in potassium mediated neuronal survival. Brain Res 502:99-108.

Collins F, Schmidt MF, Guthrie PB, Kater SB (1991) Sustained increase in intracellular calcium promotes neuronal survival. $\mathrm{J}$ Neurosci 11:2582-2587.

Cooper DMF, Mons N, Karpan JW (1995) Adenylyl cyclases and the interaction between calcium and cAMP signaling. Nature 374:421-424.

Creedon DJ, Johnson Jr EM, Lawrence Jr JC (1997) Mitogen-activated protein kinase-independent pathways mediate the effects of nerve growth factor and cAMP on neuronal survival. J Biol Chem 271:20713-20718.

Crowder RJ, Freeman RS (1998) Phosphatidylinositol 3-kinase and Akt protein kinase are necessary and sufficient for the survival of nerve growth factor-dependent sympathetic neurons. J Neurosci 18:2933-2943.

Davies AM (1996) Paracrine and autocrine actions of neurotrophic factors. Neurochem Res 21:749-753.

Dickens M, Svitek CA, Culbert AA, O'Brien RM, Tavare JM (1998) Central role for phosphatidylinositide 3-kinase in the repression of glucose-6-phosphatase gene transcription by insulin. J Biol Chem 273:20144-20149

D’Mello SR, Galli C, Ciotti T, Calissano P (1993) Induction of apoptosis in cerebellar granule neurons by low potassium: inhibition of death by insulin-like growth factor I and cAMP. Proc Natl Acad Sci USA 90:10989-10993.

D'Mello SR, Borodezt K, Soltoff SP (1997) Insulin-like growth factor and potassium depolarization maintain neuronal survival by distinct pathways: possible involvement of PI 3-kinase in IGF-1 signaling. J Neurosci 17:1548-1560.

Dudek H, Datta SD, Franke TF, Birnbaum MJ, Yao R, Cooper GM, Segal RA, Kaplan DR, Greenberg ME (1997) Regulation of neuronal survival by the serine-threonine protein kinase Akt. Science 275:661-665.

Dufourny B, Alblas J, van Teeffelen HA, van Schaik FM, van der Burg B, Steenbergh PH, Sussenbach JS (1997) Mitogenic signaling of insulinlike growth factor I in MCF-7 human breast cancer cells requires phosphatidylinositol 3-kinase and is independent of mitogen-activated protein kinase. J Biol Chem 272:31163-31171.

Elliott RC, Inturrisi CE, Black IB, Dreyfus CF (1994) An improved method detects differential NGF and BDNF gene expression in response to depolarization in cultured hippocampal neurons. Brain Res Mol Brain Res 26:81-88.

Erhardt P, Schremser EJ, Cooper GM (1999) B-Raf inhibits programmed cell death downstream of cytochrome c release from mitochondria by activating the MEK/Erk pathway. Mol Cell Biol 19:5308-5315.

Ernfors P, Duan ML, El Shamy WM, Canlon B (1996) Protection of auditory neurons from aminoglycoside toxicity by neurotrophin-3. Nat Med 2:463-467.

Franklin JL, Johnson Jr EM (1994) Block of neuronal apoptosis by a sustained increase of steady-state free $\mathrm{Ca}^{2+}$ concentration. Philos Trans R Soc Lond B Biol Sci 345:251-256.

Franklin JL, Sanz-Rodriguez C, Juhasz A, Deckwerth TL, Johnson Jr EM (1995) Chronic depolarization prevents programmed death of sympa- thetic neurons in vitro but does not support growth: requirement for $\mathrm{Ca}^{2+}$ influx but not Trk activation. J Neurosci 15:643-664.

Furber S, Oppenheim RW, Prevette D (1987) Naturally-occurring neuron death in the ciliary ganglion of the chick embryo following removal of preganglionic input: evidence for the role of afferents in ganglion cell survival. J Neurosci 7:1816-1832.

Gall CM (1992) Regulation of brain neurotrophin expression by physiological activity. Trends Pharmacol Sci 13:401-403.

Galli C, Meucci O, Scorziello A, Werge TM, Calissano P, Schettini G (1995) Apoptosis in cerebellar granule cells is blocked by high $\mathrm{KCl}$, forskolin, and IGF-1 through distinct mechanisms of action: the involvement of intracellular calcium and RNA synthesis. J Neurosci 15:1172-1179.

Galli-Resta L, Ensini M, Fusco E, Gravina A, Margheritti B (1993) Afferent spontaneous electrical activity promotes the survival of target cells in the developing retinotectal system of the rat. J Neurosci 13:243-250.

Gallo V, Kingsbury A, Balazs R, Jorgensen OS (1987) The role of depolarization in the survival and differentiation of cerebellar granule cells in culture. J Neurosci 7:2203-2213.

Ghosh A, Carnahan J, Greenberg ME (1994) Requirement for BDNF in activity-dependent survival of cortical neurons. Science 263:1618-1623

Green SH (1995) The use of PC12 cells for the study of the mechanism of action of neurotrophic factors: signal transduction and programmed cell death. Methods Companion Methods Enzymol 7:222-237.

Hack N, Hidaka H, Wakefield MJ, Balazs R (1993) Promotion of granule cell survival by high $\mathrm{K}^{+}$or excitatory amino acid treatment and $\mathrm{Ca}^{2+} /$ calmodulin-dependent protein kinase activity. Neuroscience 57:9-20.

Hanson Jr MG, Shen S, Wiemelt AP, McMorris FA, Barres BA (1998) Cyclic AMP elevation is sufficient to promote the survival of spinal motor neurons in vitro. J Neurosci 18:7361-7371.

Hanson PI, Schulman H (1992) Neuronal Ca ${ }^{2+} /$ calmodulin-dependent protein kinases. Annu Rev Biochem 61:559-601.

Harada H, Becknell B, Wilm M, Mann M, Huang LJ, Taylor SS, Scott JD, Korsmeyer SJ (1999) Phosphorylation and inactivation of BAD by mitochondria-anchored protein kinase A. Mol Cell 3:413-422.

Hartshorn DO, Miller JM, Altschuler RA (1991) Protective effect of electrical stimulation in the deafened guinea pig cochlea. Otolaryngol Head Neck Surg 104:311-319.

Hegarty JL, Kay AR, Green SH (1997) Trophic support of cultured spiral ganglion neurons by depolarization exceeds and is additive with that by neurotrophins or cAMP, and requires elevation of $\left[\mathrm{Ca}^{2+}\right]_{\mathrm{i}}$ within a set range. J Neurosci 17:1959-1970.

Isackson PJ, Huntsman MM, Murray KD, Gall CM (1991) BDNF mRNA expression is increased in adult rat forebrain after limbic seizures: temporal patterns of induction distinct from NGF. Neuron 6:937-948.

Kaiser PK, Lipton SA (1990) VIP-mediated increase in cAMP prevents tetrodotoxin-induced retinal ganglion cell death in vitro. Neuron 5:373-381.

Kauffmann-Zeh A, Rodriguez-Viciana P, Ulrich E, Gilbert C, Coffer P, Downward J, Evan G (1997) Suppression of c-Myc-induced apoptosis by Ras signalling through PI(3)K and PKB. Nature 385:544-548.

Koike T, Martin DP, Johnson Jr EM (1989) Role of $\mathrm{Ca}^{2+}$ channels in the ability of membrane depolarization to prevent neuronal death induced by trophic-factor deprivation: evidence that levels of internal $\mathrm{Ca}^{2+}$ determine nerve growth factor dependence of sympathetic ganglion cells. Proc Natl Acad Sci USA 86:6421-6425.

Koitchev K, Guilhaume A, Cazals Y, Aran JM (1982) Spiral ganglion changes after massive aminoglycoside treatment in the guinea pig. Counts and ultrastructure. Acta Otolaryngol 94:431-438.

Lachica EA, Rubsamen R, Zirpel L, Rubel EW (1995) Glutamatergic inhibition of voltage-operated calcium channels in the avian cochlear nucleus. J Neurosci 15:1724-1734.

Leake PA, Hradek GT, Rebscher SJ, Snyder RL (1991) Chronic intracochlear electrical stimulation induces selective survival of spiral ganglion neurons in neonatally deafened cats. Hearing Res 54:251-271.

Leake PA, Snyder RL, Hradek GT, Rebscher SJ (1992) Chronic intracochlear electrical stimulation in neonatally deafened cats: effects of intensity and stimulating electrode location. Hearing Res 64:99-117.

Lefebvre PP, Van de Water TR, Weber T, Rogister B, Moonen G (1991) Growth factor interactions in cultures of dissociated adult acoustic ganglia: neuronotrophic effects. Brain Res 567:306-312.

Lefebvre PP, Malgrange B, Staecker H, Moghadass M, Van De Water TR, Moonen G (1994) Neurotrophins affect survival and neuritogenesis by adult injured auditory neurons in vitro. NeuroReports 5:865-868.

Lev S, Moreno H, Martinez R, Canoll P, Peles E, Musacchio JM, Plowman GD, Rudy B, Schlessinger J (1995) Protein tyrosine kinase PYK2 involved in $\mathrm{Ca}^{2+}$-induced regulation of ion channel and MAP kinase functions. Nature 376:737-745

Lewin GR, Barde YA (1996) Physiology of the neurotrophins. Annu Rev Neurosci 19:289-317. 
Lindholm D, Castren E, Berzaghi M, Blochl A, Thoenen H (1994) Activity-dependent and hormonal regulation of neurotrophin mRNA levels in the brain-implications for neuronal plasticity. J Neurobiol 25:1362-1372

Lipton SA (1986) Blockade of electrical activity promotes the death of mammalian retinal ganglion cells in culture. Proc Natl Acad Sci USA 83:9774-9778.

Lousteau RJ (1987) Increased spiral ganglion cell survival in electrically stimulated deafened guinea pig cochleae. Laryngoscope 97:836-842.

Lustig LR, Leake PA, Snyder RL, Rebscher SJ (1994) Changes in the cat cochlear nucleus following neonatal deafening and chronic intracochlear electrical stimulation. Hearing Res 74:29-37.

Maderdrut JL, Oppenheim RW, Prevette D (1988) Enhancement of naturally-occurring cell death in the sympathetic and parasympathetic ganglia of the chicken embryo following blockade of ganglionic transmission. Brain Res 444:189-194.

Mark MD, Liu Y, Wong ST, Hinds TR, Storm DR (1995) Stimulation of neurite outgrowth in PC12 cells by EGF and $\mathrm{KCl}$ depolarization: a $\mathrm{Ca}^{2+}$-independent phenomenon. J Cell Biol 130:701-710.

Massé T, Kelly PT (1997) Overexpression of $\mathrm{Ca}^{2+} /$ calmodulindependent protein kinase II in PC12 cells alters cell growth, morphology, and nerve growth factor-induced differentiation. J Neurosci 17:924-931.

Mazzoni IE, Said FA, Aloyz R, Miller FD, Kaplan D (1999) Ras regulates sympathetic neuron survival by suppressing the p53-mediated cell death pathway. J Neurosci 19:9716-9727.

Meriney SD, Pilar G, Ogawa M, Nunez R (1987) Differential neuronal survival in the avian ciliary ganglion after chronic acetylcholine receptor blockade. J Neurosci 7:3840-3849.

Mesner PW, Epting CL, Hegarty JL, Green SH (1995) A timetable of events during programmed cell death induced by trophic factor withdrawal. J Neurosci 15:7357-7366.

Meyer-Franke A, Kaplan MR, Pfrieger FW, Barres BA (1995) Characterization of the signaling interactions that promote the survival and growth of developing retinal ganglion cells in culture. Neuron 15:805-819.

Meyer-Franke A, Wilkinson GA, Kruttgen A, Hu M, Munro E, Hanson Jr MG, Reichardt LF, Barres BA (1998) Depolarization and cAMP elevation rapidly recruit TrkB to the plasma membrane of CNS neurons. Neuron 21:681-693.

Miller TM, Tansey MG, Johnson Jr EM, Creedon DJ (1997) Inhibition of phosphatidylinositol 3-kinase activity blocks depolarization- and insulin-like growth factor I-mediated survival of cerebellar granule cells. J Biol Chem 272:9847-9853.

Mobley WC, Schenker A, Shooter EM (1972) Characterization and isolation of proteolytically modified nerve growth factor. Biochemistry 15:5543-5552.

Mou K, Hunsberger CL, Cleary JM, Davis RL (1997) Synergistic effects of BDNF and NT-3 on postnatal spiral ganglion neurons. J Comp Neurol 386:529-539.

Pang L, Sawada T, Decker SJ, Saltiel AR (1995) Inhibition of MAP kinase kinase blocks the differentiation of PC12 cells induced by nerve growth factor. J Biol Chem 270:13585-13588.

Pirvola U, Arumae U, Moshnyakov M, Palgi J, Saarma M, Ylikoski J (1994) Coordinated expression and function of neurotrophins and their receptors in the rat inner ear during target innervation. Hearing Res 75:131-144.

Rosen LB, Ginty DD, Weber MJ, Greenberg ME (1994) Membrane depolarization and calcium influx stimulate MEK and MAP kinase via activation of Ras. Neuron 12:1207-1221.

Rothermel JD, Stec WJ, Baraniak J, Jastorff B, Botelho LH (1983) Inhibition of glycogenolysis in isolated rat hepatocytes by the Rp diastereomer of adenosine cyclic $3^{\prime}, 5^{\prime}$-phosphorothioate. J Biol Chem 258:12125-12128.

Rubel EW, Hyson RL, Durham D (1990) Afferent regulation of neurons in the brain stem auditory system. J Neurobiol 21:169-196.

Rübsamen R, Lippe WR (1998) The development of cochlear function. In: Development of the auditory system (Rubel EW, Popper AN, Fay RR, eds), pp 193-270. New York: Springer.

Ruitjer JM, Baker RE, De Jong BM, Romijn HJ (1991) Chronic blockade of bioelectric activity in neonatal rat cortex grown in vitro. Morphological effects. Int J Dev Neurosci 9:331-338.

Rukenstein A, Rydel RE, Greene LA (1991) Multiple agents rescue PC12 cells from serum-free cell death by translation- and transcriptionindependent mechanisms. J Neurosci 11:2552-2563.

Rusanescu G, Qi H, Thomas SM, Brugge JS, Halegoua S (1995) Calcium influx induces neurite growth through a Src-Ras signaling cassette. Neuron 15:1415-1425.

Rydel RE, Greene LA (1988) cAMP analogs promote survival and neurite outgrowth in cultures of rat sympathetic and sensory neurons independently of nerve growth factor. Proc Natl Acad Sci USA 85:1257-1261.

Schecterson LC, Bothwell M (1994) Neurotrophin and neurotrophin receptor mRNA expression in developing inner ear. Hearing Res 73:92-100
Scott BS, Fisher KC (1970) Potassium concentration and number of neurons in cultures of dissociated ganglia. Exp Neurol 27:16-22.

Segal RA, Greenberg ME (1996) Intracellular signaling pathways activated by neurotrophic factors. Annu Rev Neurosci 19:463-489.

Shelton DL, Sutherland J, Gripp J, Camerato T, Armanini MP, Phillips HS, Carroll K, Spencer SD, Levinson AD (1995) Human trks: molecular cloning, tissue distribution, and expression of extracellular domain immunoadhesins. J Neurosci 15:477-491.

Solem M, McMahon T, Messing RO (1995) Depolarization-induced neurite outgrowth in PC12 cells requires permissive, low level NGF receptor stimulation and activation of calcium/calmodulin-dependent protein kinase. J Neurosci 15:5966-5975.

Spoendlin H (1975) Retrograde degeneration of the cochlear nerve. Acta Otolaryngol 79:266-275.

Staecker H, Kopke R, Malgrange B, Lefebvre P, Van de Water TR (1996) NT-3 and/or BDNF therapy prevents loss of auditory neurons following loss of hair cells. NeuroReport 7:889-894.

Su TZ, Wang M, Syu LJ, Saltiel AR, Oxender DL (1998) Regulation of system A amino acid transport in 3T3-L1 adipocytes by insulin. J Biol Chem 273:3173-3179.

Suzuki J, Kaziro Y, Koide H (1997) An activated mutant of R-Ras inhibits cell death caused by cytokine deprivation in BaF3 cells in the presence of IGF-I. Oncogene 15:1689-1697.

Thoenen H (1995) Neurotrophins and neuronal plasticity. Science 270:593-598.

Vaillant AR, Mazzoni I, Tudan C, Boudreau M, Kaplan DR, Miller FD (1999) Depolarization and neurotrophins converge on the phosphatidylinositol 3-kinase-Akt pathway to synergistically regulate neuronal survival. J Cell Biol 146:955-966.

Vazquez E, Van de Water TR, Del Valle M, Vega JA, Staecker H, Giráldez F, Represa J (1994) Pattern of trkB protein-like immunoreactivity in vivo and the in vitro effects of brain-derived neurotrophic factor (BDNF) on developing cochlear and vestibular neurons. Anat Embryol 189:157-167.

Virdee K, Tolkovsky AM (1996) Inhibition of p42 and p44 mitogenactivated protein kinase activity by PD98059 does not suppress nerve growth factor-induced survival of sympathetic neurones. J Neurochem 67:1801-1805.

Wagle A, Jivraj S, Garlock GL, Stapleton SR (1998) Insulin regulation of glucose-6-phosphate dehydrogenase gene expression is rapamycinsensitive and requires phosphatidylinositol 3-kinase. J Biol Chem 273:14968-14974.

Wakade AR, Edgar D, Thoenen H (1983) Both nerve growth factor and high $\mathrm{K}^{+}$concentrations support the survival of chick embryo sympathetic neurons. Evidence for a common mechanism of action. Exp Cell Res 144:377-384.

Wang D, Sul HS (1998) Insulin stimulation of the fatty acid synthase promoter is mediated by the phosphatidylinositol 3-kinase pathway. Involvement of protein kinase B/Akt. J Biol Chem 273:25420-25426.

Webster M, Webster DB (1981) Spiral ganglion neuron loss following organ of Corti loss: a quantitative study. Brain Res 212:17-30.

Wong-Riley MT, Walsh SM, Leake-Jones PA (1981) Maintenance of neuronal activity by electrical stimulation of unilaterally deafened cats demonstrable with cytochrome oxidase technique. Ann Otol Rhinol Laryngol 90:30-32.

Wright L (1981) Cell survival in chick embryo ciliary ganglion is reduced by chronic ganglionic blockade. Dev Brain Res 1:283-286.

Xia Z, Dickens M, Raingeaud J, Davis RJ, Greenberg ME (1995) Opposing effects of ERK and JNK-p38 MAP kinases on apoptosis. Science 270:1326-1331

Yan CYI, Greene LA (1998) Prevention of PC12 cell death by $\mathrm{N}$-acetylcysteine requires activation of the ras pathway. $\mathrm{J}$ Neurosci 18:4042-4049.

Yano S, Tokumitsu H, Soderling TR (1998) Calcium promotes cell survival through CaM-K kinase activation of the protein-kinase-B pathway. Nature 396:584-587.

Yao R, Cooper GM (1995) Requirement for phosphatidylinositol-3 kinase in the prevention of apoptosis by nerve growth factor. Science 267:2003-2006.

Ylikoski J, Pirvola U, Moshnyakov M, Palgi J, Arumäe U, Saarma M (1993) Expression patterns of neurotrophin and their receptor mRNAs in the rat inner ear. Hearing Res 65:69-78.

Zafra F, Hengerer B, Leibrock J, Thoenen H, Lindholm D (1990) Activity dependent regulation of BDNF and NGF mRNAs in the rat hippocampus is mediated by non-NMDA glutamate receptors. EMBO J 9:3545-3550.

Zafra F, Lindholm D, Castren E, Hartikka J, Thoenen H (1992) Regulation of brain-derived neurotrophic factor and nerve growth factor mRNA in primary cultures of hippocampal neurons and astrocytes. J Neurosci 12:4793-4799.

Zheng JL, Stewart RR, Gao WQ (1995) Neurotrophin-4/5 enhances survival of cultured spiral ganglion neurons and protects them from cisplatin neurotoxicity. J Neurosci 15:5079-5087. 